UNIVERSIDADE DE SÃO PAULO

ESCOLA DE ENFERMAGEM

FERNANDA DE SOUZA MACHADO

INTERVENÇÕES NÃO FARMACOLÓGICAS PARA O TRATAMENTO DA ALTERAÇÃO DO PADRÃO DO SONO EM PACIENTES SUBMETIDOS À CIRURGIA CARDÍACA: UMA REVISÃO SISTEMÁTICA

São Paulo

2016 
FERNANDA DE SOUZA MACHADO

\title{
INTERVENÇÕES NÃO FARMACOLÓGICAS PARA O TRATAMENTO DA ALTERAÇÃO DO PADRÃO DO SONO EM PACIENTES SUBMETIDOS À CIRURGIA CARDÍACA: UMA REVISÃO SISTEMÁTICA
}

\author{
Versão corrigida da Dissertação \\ apresentada ao Programa de Pós- \\ Graduação em Enfermagem na Saúde do \\ Adulto da Escola de Enfermagem da \\ Universidade de São Paulo para obtenção \\ do título de Mestra em Ciências \\ Área de concentração: Enfermagem na \\ Saúde do Adulto \\ Orientadora: Prof. ${ }^{\text {a }}$ Dra . Ana Lucia Siqueira \\ Costa Calache
}

\section{VERSÃO CORRIGIDA}

A versão original encontra-se disponível na Biblioteca da Escola de Enfermagem da Universidade de São Paulo e na Biblioteca Digital de Teses e Dissertações da Universidade de São Paulo.

São Paulo 
AUTORIZO A REPRODUÇÃO E DIVULGAÇÃO TOTAL OU PARCIAL DESTE TRABALHO, POR QUALQUER MEIO CONVENCIONAL OU ELETRÔNICO, PARA FINS DE ESTUDO E PESQUISA, DESDE QUE CITADA A FONTE.

Assinatura:

Data: 


\section{Catalogação na Publicação (CIP)}

Biblioteca "Wanda de Aguiar Horta"

\section{Escola de Enfermagem da Universidade de São Paulo}

Machado, Fernanda de Souza

Intervenções não farmacológicas para o tratamento da alteração do padrão do sono em pacientes submetidos à cirurgia cardíaca: uma revisão sistemática / Fernanda de Souza Machado. São Paulo, 2016.

$116 \mathrm{p}$.

Dissertação (Mestrado) - Escola de Enfermagem da Universidade de São Paulo.

Orientadora: Prof. ${ }^{\text {a }}$ Dr. ${ }^{\text {a }}$ Ana Lucia Siqueira Costa Calache

Área de concentração: Enfermagem na Saúde do Adulto

1. Enfermagem. 2. Sono. 3. Cirurgia torácica. 3. Revisão sistemática. I. Título. 


\section{FOLHA DE APROVAÇÃO}

Fernanda de Souza Machado

Intervenções não farmacológicas para o tratamento da alteração do padrão do sono em pacientes submetidos à cirurgia cardíaca: uma revisão sistemática.

Dissertação apresentada ao Programa de Pós-Graduação em Enfermagem na Saúde do Adulto da Escola de Enfermagem da Universidade de São Paulo para obtenção do título de Mestre em Ciências.

Aprovado em:

\section{Banca Examinadora}

Prof. Dr. Instituição:

Julgamento: Assinatura:

Prof. Dr. Instituição:

Julgamento: Assinatura:

Prof. Dr. Instituição:

Julgamento: Assinatura: 


\section{DEDICATÓRIA}

À minha mãe, pessoa mais importante da minha vida, minha base, meu exemplo de vida e a quem devo tudo que hoje sou.

Ao meu sobrinho que desde tão pequenino me traz alegria com seu jeito cativante e amoroso.

A todos os membros da família Souza e aos meus amigos que souberam compreender minha ausência durante esse momento árduo de estudos. 


\section{AGRADECIMENTOS}

Primeiramente, agradeço a uma força maior e inexplicável, DEUS. Sem Ele eu não teria alcançado mais esse objetivo de minha vida.

À orientadora e amiga, Prof ${ }^{a} \operatorname{Dr}^{\mathrm{a}}$ Ana Lucia Siqueira Costa Calache, pela competência, dedicação, paciência e amizade com que conduziu esse trabalho desde o início até a finalização.

À Prof ${ }^{\mathrm{a}} \mathrm{Dr}^{\mathrm{a}}$ Vanessa Brito Poveda, por suas valiosas contribuições na construção dessa pesquisa.

À minha querida amiga Isanne Lima, que fez de tudo que estava ao seu alcance para não deixar que a minha trajetória de mestranda fosse "tão sofrida" e que sempre me motivou e tranquilizou.

À amiga Regina Claudia da Silva Souza, por sua contribuição e dedicação em minha pesquisa como segunda revisora.

À amiga e coordenadora Luana Gentil, por me incentivar na pesquisa e pela colaboração em minhas escalas de trabalho.

À bibliotecária Rita de Cassia Ortega Borges, por toda sua ajuda na formatação e revisão deste trabalho. 
“...Lembra que o sono é sagrado

E alimenta de horizontes O tempo acordado de viver..."

Beto Guedes 


\section{RESUMO}

MACHADO FS. Intervenções não farmacológicas para o tratamento da alteração do padrão do sono em pacientes submetidos à cirurgia cardíaca: revisão sistemática [dissertação]. São Paulo: Escola de Enfermagem, Universidade de São Paulo; 2016.

Introdução: A alteração do padrão do sono representa um dos sintomas mais relatados pelos pacientes submetidos à cirurgia cardíaca. As características deste distúrbio incluem curto período de sono, frequentes despertares e percepção da baixa qualidade do sono pelo paciente. Como consequência dessa alteração, o paciente em período de recuperação cirúrgica apresenta-se sonolento, fadigado, irritado e pouco motivado para as terapias de reabilitação. A promoção do sono desses pacientes é um desafio para o enfermeiro. Contudo, não há evidências conclusivas sobre as melhores intervenções não farmacológicas que possam ser seguramente adotadas na prática assistencial do enfermeiro. Objetivo: Analisar as evidências disponíveis na literatura sobre as melhores intervenções não farmacológicas para o tratamento da alteração do padrão do sono em pacientes submetidos à cirurgia cardíaca. Método: Trata-se de uma revisão sistemática da literatura que foi inspirada nas recomendações propostas pela Colaboração Cochrane. A estratégia de busca nas bases eletrônicas utilizou os componentes do PICO, representada pelo acrônimo P - paciente, I - intervenção, C - controle, O "outcomes". As bases de dados investigadas foram Pubmed, Cochrane, Lilacs, Scopus, Embase, Cinahl e PsycINFO. Incluiu-se também a busca na literatura "cinzenta" utilizando as bases ProQuest Dissertations and Theses, Biblioteca Digital de Teses e Dissertações da Universidade de São Paulo, Evidence-Informed Policy Network (EVIPNet), Observatório da Produção Intelectual da Faculdade de Medicina da Universidade de São Paulo, Registro Brasileiro de Ensaios Clínicos e ClinicalTrials.gov $e$ as referências bibliográficas dos estudos incluídos. Os descritores controlados e não controlados foram delimitados para cada uma das bases de dados. Resultados: Considerando os critérios de inclusão e exclusão adotados, dez ensaios clínicos controlados e randomizados foram incluídos na revisão. $\mathrm{Na}$ síntese das evidências disponíveis, constatou-se que as intervenções não farmacológicas agruparam-se em três categorias principais: quatro estudos testaram dispositivos para minimizar a interrupção do sono e/ou sua indução; três ensaios clínicos investigaram a eficácia de técnicas de relaxamento e três estudos primários avaliaram a efetividade de intervenções educacionais. Em relação à qualidade metodológica dos estudos, $50 \%$ dos estudos foram considerados de moderada qualidade pelo escore de Jadad e outros $50 \%$, de baixa qualidade. Os resultados mostram que o uso de dispositivos foi mais frequente na prevenção ou promoção da qualidade do sono. Conclusões: Melhoria significativa nos escores de avaliação do sono foi encontrada em estudos que testaram intervenções como tampões de ouvidos, máscara de olhos, relaxamento muscular, treinamento de postura e relaxamento, produção sonora e estratégia educacional. Recomenda-se, ainda, a construção de estudos com maior rigor metodológico para que possam ser adotados seus resultados na prática assistencial. Compete ao enfermeiro a avaliação correta das necessidades dos pacientes, o planejamento, a implementação das intervenções, a supervisão e a avaliação crítica dos resultados. 
PALAVRAS-CHAVE: Enfermagem. Sono. Cirurgia cardíaca. Revisão sistemática. Intervenção não farmacológica.

\section{ABSTRACT}

MACHADO FS. Non-pharmacological interventions for the treatment of sleep pattern changes in patients undergoing cardiac surgery: a systematic review [dissertation]. São Paulo: School of Nursing, University of São Paulo; 2016.

Introduction: Disorders in the sleep pattern are among the most common symptoms reported by patients undergoing cardiac surgery. The features of these disorders include short sleep, frequent awakenings and low quality perceived by the patient. As a result of these disorders, the patient presents drowsy, fatigued, irritable and discouraged for rehabilitation therapies in the surgical recovery period. The promotion of sleep in these patients is a challenge for nurses. However, there isn't conclusive evidence about the best non-pharmacological interventions that can be adopted in care nursing practice. Purpose: This study aims to analyze the evidence available in the literature about the best non-pharmacological interventions for the treatment of disorders related to the sleep pattern in patients undergoing cardiac surgery. Method: This is a systematic review of the literature that followed the recommendations proposed by the Cochrane Collaboration. The search strategy in the electronic databases used the PICO components. The databases investigated were Pubmed, Cochrane, LiLACS, Scopus, Embase, Cinahl and PsycINFO. It was also included the search in the "gray" literature using the bases ProQuest Dissertations and Theses, Digital Library of Theses and Dissertations from the University of São Paulo, Evidence-Informed Policy Network (EVIPNet), Centre for Intellectual Production from the School of Medicine of the University of São Paulo, Brazilian registry of Clinical Trials and ClinicalTrials.gov, as well as the reference lists of the included studies. The controlled and uncontrolled descriptors were defined for each of the databases. Results: Considering the adopted inclusion and exclusion criteria, ten randomized controlled trials were included in the review. In the synthesis of the available evidence, it was found that non-pharmacological interventions were grouped into three main categories: four studies tested devices to minimize disruption of sleep and/or its induction; three clinical trials investigated the efficacy of relaxing techniques and three primary studies evaluated the effectiveness of educational interventions. Regarding to the methodological quality of the studies, we haven't found studies considered high quality by the Jadad score. Results show that the use of devices was more frequent in the prevention or promotion of sleep quality. Conclusions: Significant improvement in the scores for assessment of sleep was found in studies that tested interventions such as ear plugs, eye mask, muscle relaxation, posture training and relaxation, sound production and educational strategy. It is also recommended building studies with greater methodological precision so its results can be adopted in care practice. Nurses are responsible of evaluating correctly the patient needs, the planning and implementation of interventions, the supervision and the critical evaluation of results.

Keywords: Nursing. Sleep. Cardiac surgical procedures. Systematic review. Complementary therapies. 


\section{LISTA DE QUADROS}

Quadro 1 - Estratégia PICO para o desenvolvimento da pergunta da pesquisa da revisão sistemática

Quadro 2 - Sistema de classificação hierárquico da qualidade da evidência .43

Quadro 3 - Descritores controlados segundo base de dados .45

Quadro 4 - Estratégias de busca segundo bases de dados .48

Quadro 5 - Caracterização dos estudos primários incluídos na revisão sistemática, segundo título, autores, periódico, origem e ano de publicação .59

Quadro 6 - Distribuição dos estudos primários conforme avaliação pelo Escore de Jadad et al. ${ }^{88}$

Quadro 7 - Síntese do estudo 3 categorizado como relaxamento 64

Quadro 8 - Síntese do estudo 6 categorizado como relaxamento .66

Quadro 9 - Síntese do estudo 7 categorizado como relaxamento .68

Quadro 10 - Síntese do estudo 4 categorizado como dispositivos .70

Quadro 11 - Síntese do estudo 8 categorizado como dispositivos .72

Quadro 12 - Síntese do estudo 9 categorizado como dispositivos .75

Quadro 13 - Síntese do estudo 10 categorizado como dispositivos .78

Quadro 14 - Síntese do estudo 1 categorizado como estratégia educacional .80

Quadro 15 - Síntese do estudo 2 categorizado como estratégia educacional .82

Quadro 16 - Síntese do estudo 5 categorizado como estratégia educacional .84 


\section{LISTA DE TABELAS}

Tabela 1 - Número de estudos primários encontrados e incluídos de acordo com as bases de dados .52 


\section{LISTA DE FIGURAS}

Figura 1 - Fluxograma utilizado na seleção dos estudos da RS .54 


\section{SUMÁRIO}

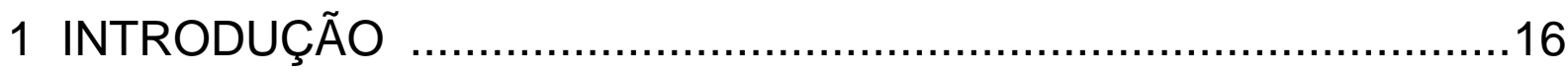

2 OBJETIVO

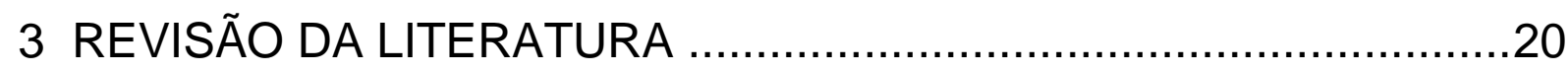

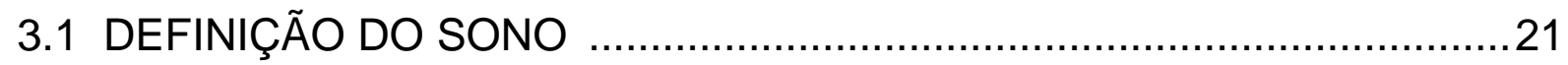

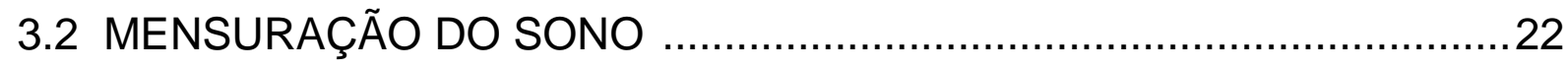

3.3 CAUSAS DA INTERRUPÇÃO DO SONO ………………………….......

3.4 CONSEQUÊNCIAS DA PRIVAÇÃO DO SONO ……………………....25

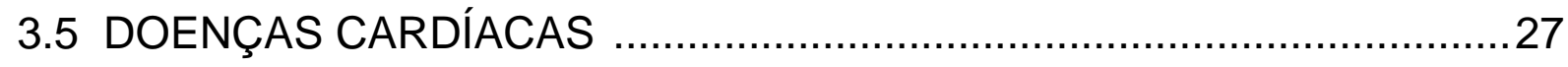

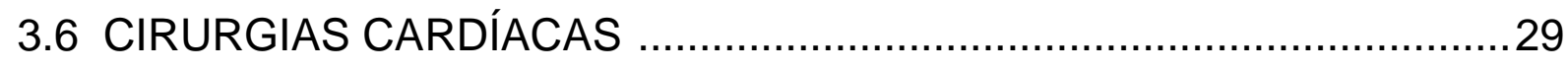

3.7 PADRÃO DO SONO DE PACIENTE SUBMETIDO À CIRURGIA

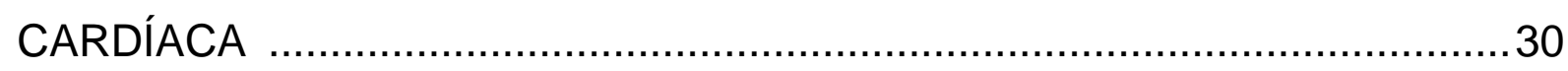

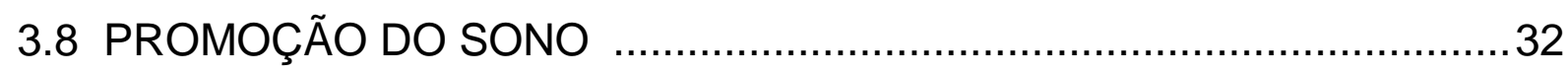

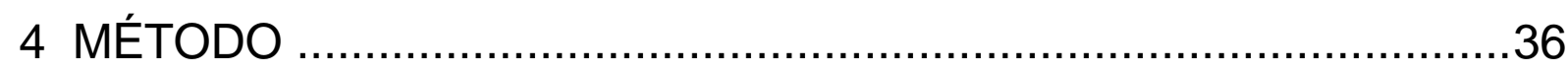

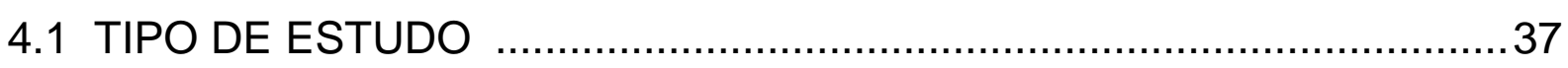

4.2 FORMULAÇÃO DA PERGUNTA DE PESQUISA …………………........39

4.3 LOCALIZAÇÃO E SELEÇÃO DOS ESTUDOS ……………………....... 41

4.4 AVALIAÇÃO CRÍTICA DOS ESTUDOS ………………………….........

4.5 ANÁLISE, INTERPRETAÇÃO E APRESENTAÇÃO DOS RESULTADOS

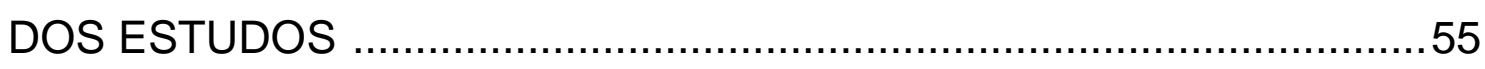

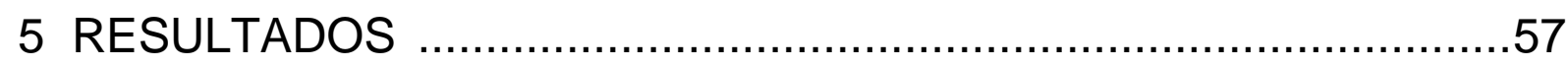


5.1 CARACTERÍSTICAS DOS ESTUDOS PRIMÁRIOS

5.2 CARACTERÍSTICAS METODOLÓGICAS DOS ESTUDOS PRIMÁRIOS

5.3 SÍNTESE DOS ESTUDOS PRIMÁRIOS SEGUNDO INTERVENÇÃO TESTADA

5.4 SÍNTESE DOS ESTUDOS PRIMÁRIOS SEGUNDO DELINEAMENTO DE ESTUDO

6 DISCUSSÃO

7 CONCLUSÕES

8 REFERÊNCIAS 103

APÊNDICE - Instrumento para coleta de dados (validado por Ursi ${ }^{81}$ ) 
A experiência profissional como enfermeira assistencial em uma Unidade de Terapia Intensiva (UTI) Cardiológica onde o perfil de pacientes é predominantemente cirúrgico despertou em mim o interesse pelas alterações que ocorrem com eles durante o período pós-operatório. Entre as principais causas de internação na UTI estão os pós-operatórios de revascularização do miocárdio, correções valvares e cirurgias da aorta.

Mesmo com poucos anos de prática profissional em Enfermagem, muitos foram os momentos nos quais me deparei com pacientes vivenciando situações conflitantes após a cirurgia, principalmente relacionadas à recuperação física, emocional e social.

Percebo nesta vivência que os principais questionamentos dos pacientes revelam ansiedade e preocupação com relação ao resultado cirúrgico. Fica evidente que a situação estressante do processo doença-hospitalização-cirurgia provoca repercussões no paciente, tais como dor, dificuldade para dormir, cansaço, alterações de humor, entre outras. É comum identificar entre os pacientes internados reclamações referentes à assistência de enfermagem, por considerarem-na responsável pelos problemas relacionados à alteração do padrão do sono. Durante o período de internação hospitalar, pacientes e seus familiares apontam que cuidados como verificação de sinais vitais, medidas hemodinâmicas, uso de equipamentos, alarmes de monitorização, exames laboratoriais, banho no leito e curativos alteram o padrão do sono.

A assistência de enfermagem ao paciente cirúrgico despertou-me inúmeras inquietações, dentre as quais a prevalência de pacientes com alteração do padrão do sono durante o período de hospitalização.

O padrão do sono é bastante estudado em pacientes adultos com câncer, fibromialgia, problemas psiquiátricos, asma e doenças cardíacas. Não obstante há ainda pouca evidência científica entre os pacientes submetidos à cirurgia cardíaca ${ }^{1}$. 
O presente estudo teve como objetivo:

- Analisar as evidências disponíveis na literatura sobre as melhores intervenções não farmacológicas para o tratamento da alteração do padrão do sono em pacientes submetidos à cirurgia cardíaca. 


\subsection{DEFINIÇÃO DO SONO}

O sono é um comportamento de saúde essencial, regulado ou influenciado por três componentes interativos: um componente do sono com a função de manter o equilíbrio relativo das oscilações diárias com os neurotransmissores do cérebro que modulam o estado de alerta/sonolência; um componente circadiano que funciona em sincronia com o ciclo ambiental de 24 horas de luz/escuro; e um componente comportamental em que os indivíduos podem interferir na regulação do sono ${ }^{2}$.

Comportamentos típicos do sono incluem os olhos fechados, postura reclinada, face e corpo relaxados, respirações profundas e regulares, pouco movimento e reduzida resposta aos estímulos ambientais ${ }^{2}$.

Outra definição sobre 0 sono traz um fenômeno multidimensional caracterizado por "(a) reduções na consciência e interações com o meio ambiente, (b) atividade muscular e motilidade reduzidos, (c) suspensão parcial ou completa do comportamento voluntário e da consciência" (Anch et al.,1988, p.2) ${ }^{3}$.

Oswald, em 1970, enfatizou que uma das principais funções do sono é a restauração física e mental. O sono foi definido como "uma baixa vigilância cerebral", momento em que ocorrem mudanças nas funções do corpo, tais como diminuição do débito urinário, queda nos valores de frequência cardíaca e pressão arterial e redução no consumo de oxigênio, que fundamentam a idéia de restauração e recuperação do corpo 4 .

Em 2007, a American Academy of Sleep Medicine (AASM) ${ }^{5}$ alterou a antiga classificação do sono de Rechtschaffen and Kales (1968) que dividia o sono em estágios vigília, 1-4 (não REM) e REM. A arquitetura normal do sono ficou então dividida em estágio W (wake/despertar), estágios N1-N3 (NREM; movimento não rápido dos olhos) e estágio $\mathrm{R}$ (REM; movimento rápido dos olhos). Entre o manual antigo e o atual, não houve diferença clínica ou fisiológica entre os estágios do sono.

O período de sono humano normal consiste em quatro a seis períodos de 60 a 110 minutos, durante os quais o estágio NREM alterna com o REM de forma cíclica. O sono NREM é dividido em três estágios, N1, N2 e N3, os quais contam 
com $2 \%$ a $5 \%$, $45 \%$ a $55 \%$ e $15 \%$ a $20 \%$ do período total do sono, respectivamente. $\mathrm{O}$ estágio $\mathrm{N} 1$ ou sono leve marca a entrada do sono para o estado de vigília. $\mathrm{O}$ estágio N2 é caracterizado por ser mais lento. Durante o estágio N3 ocorre o sono profundo, com função no processo restaurador, em especial a consolidação da memória. O sono REM conta com $20 \%$ a $25 \%$ do período total do sono; é caracterizado por movimento rápido dos olhos, variabilidade autonômica e contrações musculares somáticas. Durante o sono REM o cérebro é altamente ativo e está associado com sonhos e aprendizado perceptivo ${ }^{5}$.

Uma pesquisa comparou o significado da qualidade do sono entre dois grupos: indivíduos com sono normal e indivíduos com diagnóstico de insônia. Em ambos os grupos foram identificados como fatores mais importantes para julgar a qualidade do sono a sensação de acordar descansado, restaurado e manter-se alerta durante o dia ${ }^{6}$.

\subsection{MENSURAÇÃO DO SONO}

Como o sono é um fenômeno multidimensional biocomportamental com sensações objetivas e subjetivas, há uma variedade de métodos fisiológicos, comportamentais e de autorrelato disponíveis para mensurar o sono normal ${ }^{2}$.

As técnicas utililizadas para mensurar o sono de pacientes são classificadas como objetivas e subjetivas. As objetivas incluem polissonografia (PSG), eletroencefalograma, índice bispectral (BIS) e actigrafia. As subjetivas são realizadas por meio de questionários, escalas e autorrelatos ${ }^{2}$.

A PSG é o método que avalia os parâmetros fisiológicos do sono. Medidas comportamentais incluem actigrafia, observação direta e vídeo. Como métodos de autorrelato estão as escalas, entrevistas e diário do sono ${ }^{2}$. A PSG fornece informações mais detalhadas. É considerada o padrão ouro para qualificação e quantificação do sono de pacientes. Entretanto, é uma técnica onerosa e pouco prática para uso em pacientes críticos ${ }^{7}$.

Actigrafia e diário do sono são comumente utilizados para mensurar o sono de pacientes internados. O Pittsburgh Sleep Quality Index (PSQI) avalia retrospectivamente o sono habitual ${ }^{8}$. A actigrafia é baseada no princípio do 
movimento. Durante o sono há uma redução do movimento em relação ao estado de vigília. A mensuração ocorre por meio de um acelerômetro que detecta o movimento do pulso; ao final da avaliação, as informações são transferidas para um computador para proceder a análise dos dados. As estimativas de sono e vigília são derivadas de parâmetros como duração total do sono, frequência e duração de despertares e porcentagem de tempo gasto entre estar acordado, o início do sono e o despertar final $^{9}$. As vantagens da actigrafia incluem a ausência de influência das expectativas do paciente, inexistência de viés de memória e possibilidade da realização em domicílio $^{10}$. Apresenta $87 \%$ de sensibilidade e $90 \%$ de especificidade em diferenciar o sono de vigília ${ }^{11}$. Na ausência da PSG, a AASM recomenda o uso da actigrafia para mensuração objetiva do sono em estudos de campos $^{10}$.

O uso do diário do sono fornece informações sobre a variabilidade diária do sono e é pouco influenciado por viés de memória devido ao fato de ser preenchido diariamente. Os registros podem sofrer a influência das expectativas do paciente sobre o sono ${ }^{10}$. Não obstante, a avaliação por autorrelato tem sua importância por retratar informações sobre a percepção do paciente sobre a qualidade do sono ${ }^{2}$.

Segundo Liao et al., evidenciou-se que os três métodos mais comuns utilizados na prática clínica para mensuração do padrão do sono são PSG, actigrafia e questionário de autorrelato do sono ${ }^{12}$.

Os parâmetros utilizados na mensuração objetiva ou subjetiva do sono são os seguintes ${ }^{13}$ :

1. Tempo total de sono: tempo em minutos de sono, período consolidado de sono que ocorre durante a noite;

2. Latência do sono: tempo gasto em minutos entre deitar na cama para dormir e realmente adormecer;

3. Despertares durante o sono: número de despertares durante o período de sono;

4. Tempo acordado após início do sono: porcentagem de tempo acordado após início do sono durante o período de sono;

5. Cochilos durante o dia: tempo em minutos de sono durante o dia, que pode ser intencional ou não;

6. Sonolência excessiva diurna: recaídas de sono de curta duração; 
7. Qualidade do sono percebido: percepções de tamanho e profundidade do sono, sentimentos de estar descansado ao acordar, avaliação subjetiva de sono suficiente para o bom funcionamento diurno;

8. Ritmo circadiano: fenômeno biocomportamental associado com flutuações na luz, hormônios e/ou socialização que se repete a cada 24 horas;

9. Eficiência do sono: método alternativo de representar a quantidade de sono. É o número de minutos de sono dividido pelo total de minutos na cama multiplicado por cem $^{13}$.

As Escalas Visuais Análogas de Sono (EVA - Sono) permitem avaliar o sono de pacientes durante o período de hospitalização e, também, contribuem para que se proponham intervenções quando houver alteração desta funcionalidade. As escalas surgiram da adaptação e validação da Visual Analog Sleep Scales para a língua portuguesa considerando a importância de se avaliar o sono na prática assistencial de pacientes hospitalizados. As escalas avaliam a percepção do sono no dia anterior à avaliação ${ }^{14}$.

O sono de um adulto compreende um período consolidado de seis a oito horas de tempo total de sono que ocorre à noite a cada período de 24 horas. A eficiência do sono esperada para um indivíduo saudável é de aproximadamente 80 a $85 \%$. A duração total e a eficiência do sono declinam com o avançar da idade ${ }^{15}$.

\subsection{CAUSAS DA INTERRUPÇÃO DO SONO}

A limitação do sono pode decorrer de redução da qualidade ou quantidade do sono ou desajuste do ritmo circadiano ${ }^{16}$. A qualidade, continuidade e profundidade do sono de um paciente são alteradas por múltiplos fatores em uma situação aguda, dentre os quais idade, gênero, condição de saúde, tratamentos, ambiente, dor, fadiga, alterações psicológicas e distúrbios do sono prévios ${ }^{17,18}$.

Alguns autores consideram contribuintes para os distúrbios do sono de pacientes internados fatores como, dor pós-operatória, cuidados de enfermagem durante a noite, frequentes medidas de sinais vitais e ansiedade ${ }^{19}$. 
Um estudo realizado em um hospital brasileiro apontou iluminação excessiva, dor, fadiga e recebimento da assistência de enfermagem como os fatores mais relatados pelos pacientes como causadores da interrupção do sono. Notou-se que os pacientes queixam-se mais de fatores ambientais do que fisiológicos como causas da alteração do padrão do sono ${ }^{20}$.

Outros autores citaram alguns contribuintes diferentes para a privação do sono dos pacientes: posição desconfortável, cama não familiar, procedimentos durante a noite, ruído e iluminação ${ }^{21,22}$.

Uma pesquisa com pacientes internados avaliou os ruídos que mais frequentemente interromperam o sono. Os autores construíram um questionário baseado na literatura e opinião de especialistas que continha quinze ruídos diferentes. O próprio paciente respondia sim ou não com base no sono das duas últimas noites. $\mathrm{O}$ alarme sonoro foi $\mathrm{o}$ ruído mais citado pelos participantes como perturbador do sono ${ }^{23}$.

A idade avançada, perfil da maioria dos pacientes submetidos à cirurgia cardíaca, é um fator que pode contribuir para o distúrbio do sono, pois a eficiência do sono diminui com a progressão da idade ${ }^{17}$.

Os tratamentos utilizados no período perioperatório também exercem forte influência sobre a qualidade do sono. Cirurgia cardíaca sem o uso da circulação extracorpórea, anestésicos menos agressivos que favorecem a extubação precoce do paciente e adequada analgesia minimizam as chances de distúrbios do sono no período pós-opertório ${ }^{17}$.

\subsection{CONSEQUÊNCIAS DA PRIVAÇÃO DO SONO}

A privação do sono provoca alterações no organismo do paciente, tais como estresse, delirium, cognição debilitada e fadiga. Alterações fisiológicas como dor, aumento da frequência cardíaca e pressão arterial também podem ocorrer ${ }^{18}$.

Zhong et al. ${ }^{24}$ demonstraram que a privação do sono pode causar resultados negativos até em indivíduos jovens saudáveis. A pesquisa avaliou o sono por meio da PSG entre jovens de 18 a 40 anos de idade e evidenciou que, com 12 horas de privação do sono, há alteração no sistema nervoso autonômico do indivíduo. Há 
aumento do tônus simpático, diminuição do parassimpático e elevação das catecolaminas, resultando em labilidade da pressão arterial e da frequência cardíaca, com consequente aumento do risco de ocorrência de infarto agudo do miocárdio.

Um estudo publicado, em 1999, na Lancet também relata as evidências que explicam o motivo pelo qual a curta duração do sono está associada ao aumento da taxa de mortalidade por doenças cardiovasculares. Além do aumento da atividade do sistema nervoso simpático, ocorre alteração nos níveis de cortisol e intolerância à glicose $e^{25}$.

Há tempos é estudado que a fragmentação do sono provoca malefícios ao organismo. Outro estudo em indivíduos saudáveis mostrou que a privação do sono por um período de 24 a 30 horas foi associada ao aumento da fadiga muscular respiratória ${ }^{26}$.

Outros estudos demonstraram associação entre alteração do padrão do sono e repercussões cardiovasculares, como aterosclerose, doença arterial coronariana e hipertensão arterial. O indivíduo com o sono debilitado apresenta liberação de citocinas inflamatórias com consequentes rupturas endoteliais ${ }^{27,28}$.

A quantidade inadequada de sono por noite está relacionada a eventos adversos à saúde, incluindo a mortalidade. Há décadas, estudos mostram essa relação e enfatizam que a quantidade de tempo gasto com o sono diariamente representa um importante fator para a saúde do ser humano ${ }^{29-31}$.

Desde 1964, os efeitos deletérios da duração inadequada do sono são conhecidos. Nesse ano, um estudo em pacientes com câncer mostrou que os participantes com duração do sono em torno de sete horas por noite apresentaram menores taxas de mortalidade do que aqueles cuja duração do sono era menor ou maior. Os pacientes com duração do sono menor que quatro horas por noite foram os que apresentaram as maiores taxas de mortalidade ${ }^{32}$.

Outro estudo mostrou os impactos negativos em pacientes que dormem menos de quatro horas por noite. Uma coorte de 98.634 pacientes japoneses com follow-up de 14,3 anos mostrou que mulheres com duração do sono menor ou igual a quatro horas por dia apresentaram aumento na mortalidade por doença arterial 
coronariana. Em ambos os sexos, houve aumento da mortalidade por causas não cardíacas, não câncer e todas as outras causas ${ }^{33}$.

O sono de curta duração pode implicar efeitos fisiológicos e sociais ao ser humano, que provocam doenças cardiovasculares, câncer, acidentes cerebrovasculares, hipertensão arterial e diabetes. Essas alterações podem ocorrer por processos inflamatórios, metabólicos, estresse fisiológico e fatores socioeconômicos ${ }^{34}$.

Um estudo experimental testou a relação entre a privação do sono de indivíduos saudáveis e os níveis de proteína $C$ reativa $(P C R)$, um importante marcador inflamatório que tem sido mostrado como preditivo de morbidade cardiovascular. Houve aumento nos níveis de PCR entre os participantes com privação parcial ou total do sono, sugerindo que o sono de menor duração é um dos contribuintes para a instalação do processo inflamatório e consequente aumento na morbidade ${ }^{35}$.

Reduzidas horas de sono por noite podem contribuir para o desenvolvimento de obesidade e diabetes por pelo menos três aspectos distintos: alteração do apetite, reduzido gasto energético e alteração do metabolismo da glicose ${ }^{36}$.

\subsection{DOENÇAS CARDÍACAS}

As doenças cardiovasculares são a principal causa de morbimortalidade em todo o mundo, tornando-se ainda mais preocupantes à medida que ocorre o envelhecimento populacional ${ }^{37,38}$.

A doença arterial coronariana (DAC) representa uma das principais causas de morte do século $X X I^{39}$. Pode ocorrer por obstrução total ou redução do fluxo sanguíneo em uma ou mais artérias coronárias com lesões ateroscleróticas e por disfunção endotelial ou alteração do tônus vascular, que levam à isquemia miocárdica.

O tratamento da DAC objetiva prevenir o infarto agudo do miocárdio, reduzir a morbimortalidade, melhorar a qualidade de vida e a função ventricular, aliviar os sintomas e diminuir a ocorrência da isquemia miocárdica. Assim, conforme a estratificação do risco, há pacientes com indicação para tratamento conservador e 
outros candidatos à terapia de reperfusão coronariana. As opções terapêuticas vão desde mudança de estilos de vida e redução dos fatores de risco, como cessação do tabagismo, atividade física e dietoterapia, a intervenções medicamentosas, cirúrgicas e percutâneas ${ }^{40}$.

No Brasil, a doença valvar contribui com os números de internação hospitalar por doenças cardiovasculares. A febre reumática é a principal etiologia das valvopatias, responsável por até $70 \%$ dos $\operatorname{casos}^{41}$.

A valvopatia mitral reumática mais comum é a dupla disfunção, caracterizada por estenose (lesões crônicas) e insuficiência (lesão aguda). Como segunda causa mais frequente de insuficiência mitral está o prolapso da valva mitral, cuja evolução depende da intensidade do prolapso ${ }^{41}$.

A valvopatia aórtica em indivíduos jovens está relacionada às doenças reumática e congênita, enquanto nos idosos a causa é a doença aórtica calcificada associada a fatores de riscos ateroscleróticos (dislipidemia, hipertensão arterial e tabagismo $)^{41}$.

O tratamento da valvopatia envolve a intervenção cirúrgica ou minimamente invasiva e a terapia medicamentosa. A primeira é a única opção terapêutica capaz de alterar a evolução natural da doença valvar e a outra apenas proporciona controle dos sintomas e comorbidades ${ }^{41}$.

Uma porção significativa de pacientes com valvopatia apresenta também DAC. Mais de um terço dos pacientes com estenose aórtica apresentam as doenças concomitantemente ${ }^{41}$.

Anualmente, mais pessoas morrem por doenças cardiovasculares do que por qualquer outra causa. Estima-se que, em 2012, mais de 17 milhões de óbitos causados por doenças coronarianas e cerebrovasculares, o que representa $31 \%$ de todas as mortes no mundo ${ }^{37}$.

Os últimos dados brasileiros publicados pelo Ministério da Saúde mostraram que, em 2013, o número de óbitos por doenças do aparelho circulatório foi 339.672, sendo as principais causas as doenças isquêmicas, seguidas das cerebrovasculares. Entre os óbitos, a faixa etária mais comprometida foi a de 80 
anos, residentes na Região Sudeste do país (quase $50 \%$ do total) e mais da metade homens ${ }^{42,43}$.

Entre as doenças cardiovasculares, como acidente vascular cerebral, insuficiência cardíaca e hipertensão arterial, observou-se que a DAC apresentou maior taxa de mortalidade na população americana em 2011, com cifras superiores a 370 mil óbitos. Neste período, as doenças cardiovasculares contabilizaram mais de $30 \%$ de todas as causas de morte entre os americanos ${ }^{44}$.

Em 2012, uma estimativa mostrou que mais de 85 milhões de adultos americanos têm, no mínimo, um tipo de doença cardiovascular, e seu número aumenta com o passar da idade. Projeção recente para o ano de 2030 estima que mais de $40 \%$ da população terá algum tipo de doença cardiovascular ${ }^{44}$.

No ano de 2014, no Brasil, as doenças do aparelho circulatório foram responsáveis por mais de um milhão de internações, sendo a principal causa as doenças isquêmicas em indivíduos na faixa etária entre 60 e 79 anos $^{43}$.

\subsection{CIRURGIAS CARDÍACAS}

A revascularização do miocárdio $(\mathrm{RM})$ é a cirurgia cardíaca mais comumente realizada em todo o mundo ${ }^{45-47}$ e se tornou o tratamento padrão para pacientes com DAC, especialmente aqueles com obstrução significativa ${ }^{45,46}$. É um procedimento em que veias ou artérias autólogas são utilizadas como enxertos para revascularizar as artérias coronárias parcial ou totalmente obstruídas ${ }^{48}$.

Segundo a Sociedade Brasileira de Cardiologia, define-se lesão coronariana significativa com necessidade de intervenção cirúrgica mediante os seguintes critérios: "lesão de tronco da coronária esquerda; doença triarterial com disfunção ventricular; lesão biarterial com comprometimento proximal da artéria descendente anterior (DA) e disfunção ventricular ou presença de isquemia provocada; lesão uni ou biarterial sem comprometimento proximal da DA com critérios de alto risco nos testes não invasivos e extensa área do miocárdio em risco" ${ }^{49}$.

A cirurgia proporciona ao paciente a redução dos sintomas associados à DAC, aumento na expectativa e melhora da qualidade de vida. Atualmente, baixas 
taxas de mortalidade perioperatória estão associadas aos avanços nas técnicas cirúrgicas, ao aprimoramento medicamentoso e à assistência pós-operatória ${ }^{47}$.

Nos Estados Unidos, anualmente, mais de 400 mil pacientes são submetidos à cirurgia de $\mathrm{RM}^{44,48}$ No ano de 2010 , mais de sete milhões de pacientes realizaram procedimentos cirúrgicos cardiovasculares, o que representa a segunda maior taxa de cirurgia por diagnóstico, abaixo apenas dos procedimentos obstétricos ${ }^{44}$.

Desde a invenção desta técnica cirúrgica, nos anos 60, a demanda por esse tratamento tem aumentado constantemente ${ }^{50}$. Essa terapia tem sido amplamente estudada e atualmente possui uma gama de evidências que fortalecem e justificam a realização do procedimento ${ }^{51}$. Em virtude das inúmeras pesquisas relacionadas à revascularização cirúrgica e dos consequentes avanços na realização do procedimento, a técnica evoluiu para um processo refinado, seguro e eficiente. Portanto, os riscos perioperatórios têm diminuído constantemente, mesmo com a idade avançada frequentemente associada a essa população ${ }^{51}$. A taxa de mortalidade após cirurgia eletiva de RM mantém-se em declínio, em torno de 1 a $3 \%{ }^{52,53}$.

\subsection{PADRÃO DO SONO DE PACIENTE SUBMETIDO À CIRURGIA CARDÍACA}

O padrão do sono de paciente submetido à cirurgia cardíaca é alterado ao longo do período de recuperação ${ }^{17}$. As características objetivas e subjetivas do sono desse paciente incluem curto período de sono, fragmentação, frequentes despertares e baixa qualidade do sono pelo autorrelato ${ }^{13,17}$.

Como consequência do sono fragmentado, o paciente apresenta mais sonolência diurna, fadiga e irritabilidade, que podem reduzir a motivação para as terapias de reabilitação, atrasar o período de recuperação e aumentar o tempo de internação hospitalar ${ }^{19,54}$.

O paciente submetido à cirurgia cardíaca com o uso da circulação extracorpórea (CEC) apresenta importantes respostas ao estresse e processo inflamatório, que podem resultar em complicações pós-operatórias, como arritmias, distúrbios metabólicos e de cicatrização ${ }^{55}$. Associado a isso, a alteração do ciclo 
sono-vigília, que ocorre no período pós-operatório, pode aumentar a liberação de hormônios do estresse e substâncias inflamatórias, culminando em aumento da incidência de complicações pós-operatórias.

Estudo com pacientes submetidos à RM com CEC mostrou forte correlação entre níveis de cortisol e índice de fragmentação do sono, bem como entre proteína C reativa $(P C R)$ e eficiência do sono. A mensuração do sono nesse estudo exploratório foi realizada com uso de técnica objetiva, a actigrafia ${ }^{1}$.

Está bem estabelecido que a cirurgia de RM é uma modalidade de tratamento oferecida aos pacientes com DAC grave que apresenta resultados efetivos e seguros. Porém, um estudo comparou a qualidade de vida dos pacientes antes e após a cirurgia de RM e mostrou melhora em todos os domínios avaliados, exceto no domínio sono. Observou-se significante alteração do padrão do sono em pacientes no período pós-operatório imediato e no segundo dia pós-cirúrgico. Nesse estudo, o padrão do sono desses pacientes retornou ao nível normal após um mês do procedimento ${ }^{56}$.

Os estudos mostram que a dificuldade para dormir faz parte dos sintomas relatados pelos pacientes submetidos à cirurgia cardíaca, sugerindo interferência na recuperação física, emocional e social ${ }^{17,57}$.

Em estudo prospectivo realizado com pacientes do sexo masculino, com idade média de 60 anos, em pós-operatório de cirurgias cardiovasculares e neurológicas, verificou-se alteração do padrão do sono que se iniciou no período de internação na UTI e se manteve após alta para a unidade de internação nos dois dias subsequentes ${ }^{58}$.

Pröpper et al. mostraram pior qualidade do sono de pacientes um mês após a cirurgia cardíaca comparada aos escores prévios. Os autores utilizaram o PSQI para avaliar o padrão do sono antes e um mês após a cirurgia. Os fatores intervenientes da qualidade do sono relatados por esses pacientes foram cama desconfortável, dor e ruído de equipamentos ${ }^{59}$.

Redeker, Ruggiero e Hedges demonstraram que pacientes submetidos à cirurgia cardíaca apresentaram distúrbios do sono desde o período pré-operatório até a oitava semana de pós-operatório. As piores alterações foram evidenciadas na primeira semana após a cirurgia ${ }^{54}$. 
Um estudo fez uma análise retrospectiva sobre as anotações de enfermagem para avaliar o sono e a vigília dos pacientes nas primeiras quatro noites após a cirurgia de RM. As causas fisiológicas, como dor, náusea, vômitos e tosse, foram as mais registradas como perturbadoras do sono dos pacientes. $\mathrm{O}$ uso de dispositivos invasivos, como drenos, sondas e cateteres, também foi apontado ${ }^{60}$.

\subsection{PROMOÇÃO DO SONO}

É necessário compreender os possíveis causadores da interrupção do sono, que pode ser multifatorial, para desenvolver estratégias terapêuticas efetivas que englobam desde o manejo de sintomas, como dor e náuseas, até o controle ambiental, como redução de ruído e luminosidade ${ }^{12,17}$.

Inúmeras técnicas estão sendo testadas para promover o sono dos pacientes internados. Uma delas é o agrupamento dos cuidados de enfermagem para minimizar as interrupções do sono ${ }^{61}$. Tamburri et al. mostraram que diminuir as interações com os pacientes para os cuidados durante o período noturno pode aumentar as oportunidades de sono do paciente ${ }^{62}$.

Outro estudo evidenciou que planejar melhor as intervenções de enfermagem, minimizar interrupções desnecessárias e modificar fatores que causam ruído e luminosidade excessivos durante a noite podem contribuir para a qualidade do sono do paciente hospitalizado. Os participantes dessa pesquisa apontaram como fatores intervenientes na qualidade do sono acordar cedo, fragmentação do sono e recebimento de cuidados de enfermagem ${ }^{20}$.

Compete ao enfermeiro uma adequada avaliação diária do sono do paciente internado e a tomada de decisão sobre as intervenções para tratamento dessa alteração. A prática do enfermeiro envolve a definição de uma situação problema, fatores relacionados, diagnósticos e intervenções de enfermagem e avaliação de resultados.

Segundo a classificação da North American Diagnosis Association (NANDA) e Nursing Outcomes Classification (NOC) algumas intervenções de enfermagem já foram padronizadas para o diagnóstico de enfermagem "Padrão de Sono Prejudicado". Neste sentido destaca-se intervenções para a melhoria do 
enfrentamento, aumento da segurança, controle da dor, terapias de relaxamento muscular, processo de meditação, suporte emocional, controle ambiental, massagem, musicoterapia, terapia com animais, redução da ansiedade, posicionamento, controle da náusea e cuidados na incontinência urinária ${ }^{63}$.

Estudos sugerem que uma combinação entre redução da ansiedade e da dor, controle de fatores ambientais e tratamento apropriado da doença do paciente é eficaz para diminuir a incidência de distúrbios do sono ${ }^{61,64}$.

Uma pesquisa sugere que os enfermeiros devem priorizar intervenções que reduzam os ruídos ambientais, com atenção aos alarmes sonoros de monitores e equipamentos e conversas nos corredores ${ }^{23}$.

Um estudo de $\mathrm{Hu}$ et al. demonstrou que o sono de indivíduos saudáveis foi alterado após exposição a ambiente simulado com luminosidade e ruído. Os sujeitos dessa pesquisa relataram sensação de baixa qualidade do sono e, por meio da PSG, constataram mais sono leve, maior latência REM e menos sono REM. Nesse caso, o uso de tampões de ouvido e máscara para os olhos mostrou benefício notável com relação ao distúrbio do sono ${ }^{65}$.

O ruído e a luminosidade são fatores perturbadores do sono do paciente e estão associados a efeitos negativos fisiológicos e psicológicos, mas não são os únicos fatores responsáveis pela fragmentação do sono. Há ênfase sobre redução do ruído e escurecimento das luzes no ambiente hospitalar durante a noite, porém há pacientes críticos que precisam estar em contínua observação e necessitam de atividades para o cuidado. Sendo assim, o resultado desse estudo sugere que o uso de tampões de ouvidos e máscara de olhos possa ser uma alternativa eficaz para distúrbios do sono de pacientes internados ${ }^{65}$.

Os estudos têm mostrado que os dispositivos de proteção ao ruído e à luminosidade, além de serem efetivos e de fácil disponibilidade, têm boa aceitação entre os pacientes, por possibilitarem autocontrole sobre o uso ${ }^{65,66}$.

Le Guen et al. avaliaram a efetividade do uso de máscara para olhos e tampões de ouvido em pacientes internados em UTI de pós-operatório de cirurgias gerais. O sono dos pacientes foi mensurado objetivamente por meio da actigrafia e subjetivamente por meio de escala e autorrelato. Os pacientes do grupo controle 
apresentaram piora significativa do padrão do sono, comparado ao sono avaliado no pré-operatório, enquanto o grupo intervenção não apresentou alteração. Entretanto, esses resultados foram extraídos por meio de escala e autorrelato; a actigrafia não demonstrou diferença no padrão do sono entre os grupos do estudo. Não obstante, o estudo sugere que, pelo fato de os dispositivos (máscara de olhos e ouvido) serem baratos, simples, seguros e, principalmente, por terem sido associados a mais conforto ao paciente, representam uma ótima relação custo-benefício e são mais viáveis do que tentar diminuir o ruído e a luminosidade do ambiente ${ }^{67}$.

Na prática clínica, é essencial controlar ou atenuar os vários fatores que interrompem o sono do paciente internado e maximizar a possibilidade de proporcionar um sono restaurador ${ }^{66}$.

Os estudos têm mostrado ótimos resultados para a promoção do sono e recuperação do paciente internado por meio do uso de dispositivos como os tampões de ouvidos e máscara de olhos. Estes são simples, de fácil acesso e aceitação, além de apresentarem ótima relação custo-benefício ${ }^{65-67}$.

A literatura científica aponta para estudos que avaliam quais fatores alteram o sono do paciente submetido à cirurgia cardíaca e consequências da privação do sono $^{17,23}$. No entanto, estudos de revisão que abordem intervenções não farmacológicas para promoção do sono foram encontrados apenas com pacientes gerais hospitalizados e pacientes com câncer ${ }^{68,69}$.

Considerando que a alteração do padrão do sono é resultante de diversos fatores e o tratamento do fator causal é aspecto fundamental para obter a melhoria do desconforto do paciente, supõe-se que existam possibilidades terapêuticas não farmacológicas a serem consideradas. Orientações, tratamento da dor e diminuição do nível de ruído podem ser aspectos colaborativos na resolução do problema do sono do paciente. A correta avaliação clínica do paciente e o tratamento individualizado são essenciais para garantir uma assistência de qualidade e contribuir para a recuperação psicofisiológica.

Assim, a presente revisão justifica-se pelo fato de a alteração do padrão do sono ser um problema comum entre pacientes cardíacos ${ }^{17}$, ser vista como um grande sofrimento físico após a cirurgia cardíaca ${ }^{57}$, por representar um dos sintomas 
mais relatados pelos pacientes submetidos à cirurgia cardíaca ${ }^{70}$ e pelo fato de 0 sono ser uma necessidade humana básica que merece toda a atenção.

Espera-se que os resultados evidenciados na atual revisão sistemática possibilitem a geração de evidências que contribuam para a melhoria da prática clínica, com foco nas intervenções não farmacológicas para a promoção do sono, recuperação e conforto do paciente cardiológico. Além disso, que se desperte nos enfermeiros e equipe de saúde a importância do sono dos pacientes e o interesse em melhorar a qualidade do sono durante a internação. 
4 MÉTODO 


\subsection{TIPO DE ESTUDO}

Trata-se de uma pesquisa de revisão sistemática da literatura científica.

A revisão sistemática (RS) é parte fundamental das práticas baseadas em evidências (PBE). Este movimento surgiu após a constatação de que os resultados de pesquisas não alcançavam à prática clínica, ou seja, os médicos e os pacientes que recebiam o cuidado, de forma confiável e atual. O movimento da PBE se desenvolveu com o intuito de diminuir a lacuna entre a pesquisa e a prática ${ }^{71}$.

O objetivo da PBE é aprimorar o cuidado através da associação entre a melhor evidência científica disponível, a experiência clínica do profissional e as preferências do paciente. Visa também eliminar as práticas ineficientes e minimizar a lacuna entre a geração da evidência e sua aplicação na prática do cuidado ${ }^{72}$. Sackett $^{71}$ ainda refere que a PBE se utiliza das evidências de maneira conscienciosa, explícita e judiciosa para a tomada de decisão no cuidado do paciente.

A realização da $\mathrm{PBE}$ na assistência à saúde segue alguns passos imprescindíveis: formulação de questões respondíveis, busca de evidências, avaliação crítica, verificação da aplicabilidade da evidência e avaliação do desempenho ${ }^{72}$.

A RS, parte fundamental da PBE, é um recurso onde os resultados da pesquisa são coletados, categorizados, avaliados e sintetizados. Segundo o Handbook para Revisão Sistemática da Colaboração Cochrane versão $4.2 .5^{73}$ define RS como um método comum de pesquisa que abrange uma pergunta clínica bem formulada, busca exaustiva na literatura, identificação, seleção e avaliação crítica das evidências disponíveis, extração de dados e síntese de conteúdo dos estudos primários.

O documento do Ministério da Saúde - "Diretrizes Metodológicas: elaboração de revisão sistemática e metanálise de ensaios clínicos randomizados"74, elaborado com base em duas diretrizes internacionais utilizadas para realizar revisões sistemáticas de pesquisas clínicas, a The Cochrane Reviewer's Handbook e diretriz 
elaborada pelo grupo The Australian National Health and Medical Research Council, define RS como

\begin{abstract}
"um método de síntese de evidências que avalia criticamente e interpreta todas as pesquisas relevantes disponíveis para uma questão particular, área do conhecimento ou fenômeno de interesse. Por se tratar de método explícito e sistemático para identificar, selecionar e avaliar a qualidade de evidências, as revisões sistemáticas são tipos de estudos produzidos por uma metodologia confiável, rigorosa e auditável. Os métodos estatísticos metanálises, normalmente são inseridos na análise e síntese dos resultados, permitindo aumentar a amostra e a precisão dos desfechos avaliados" (Brasil. Ministério da Saúde. Secretaria de Ciência, Tecnologia e Insumos Estratégicos. Departamento de Ciência e Tecnologia. Diretrizes metodológicas: elaboração de revisão sistemática e metanálise de ensaios clínicos randomizados." (Brasil, 2012, p.92).
\end{abstract}

Para a execução da presente RS, foram percorridas as etapas conforme recomendações do Handbook para Revisão Sistemática da Colaboração Cochrane como se segue ${ }^{73}$ :

$\checkmark$ Primeiro passo - formulação da pergunta: a pergunta deverá ser bem formulada para evitar decisões errôneas sobre o que deverá ou não ser incluído na revisão. Neste contexto, o passo inicial da RS deverá conter de maneira bem definida os pacientes/doenças e a intervenção.

$\checkmark$ Segundo passo - localização e seleção dos estudos: para identificação dos estudos, diversas bases de dados eletrônicas deverão ser utilizadas (Pubmed/ Medline, Embase, LiLACS, Cochrane Library), busca por referências bibliográficas dos estudos relevantes, busca por estudos e pesquisas manualmente em revistas e anais de congressos. Para cada fonte utilizada o método utilizado deverá ser detalhado.

$\checkmark$ Terceiro passo - avaliação crítica dos estudos: utilização de critérios para determinar a validade dos estudos selecionados e verificar a probabilidade de as conclusões estarem baseadas em dados viciados. A avaliação determinará os estudos válidos para inclusão na revisão. Será necessário justificar o motivo pelo qual os estudos excluídos não preencheram os critérios de inclusão. 
$\checkmark$ Quarto passo - coleta de dados: as variáveis estudadas deverão estar presentes nos estudos e resumidas, assim como a inclusão das características do método, dos participantes e dos desfechos clínicos que irão determinar a possibilidade de comparação ou não dos estudos selecionados. Caso seja necessário, o contato com o autor dos estudos deverá ser realizado para maior detalhamento dos resultados presentes.

$\checkmark$ Quinto passo - análise e apresentação dos dados: os estudos poderão ser agrupados para metanálise, conforme a semelhança entre eles. O projeto deverá apresentar os agrupamentos preestabelecidos e conter, ainda, a forma de apresentação gráfica e numérica para facilitar o entendimento do leitor.

$\checkmark$ Sexto passo - interpretação dos dados: a força da evidência encontrada é determinada, assim como a aplicabilidade dos resultados, informações sobre custo e prática relevantes, os limites e os benefícios e riscos.

$\checkmark$ Sétimo passo - atualização e melhora da revisão: ao ser publicada a revisão, a mesma poderá sofrer críticas e as sugestões poderão ser incorporadas às futuras atualizações. Poderá ser considerada uma publicação viva e ser atualizada a cada nova publicação.

\subsection{FORMULAÇÃO DA PERGUNTA DE PESQUISA}

A questão de pesquisa surge a partir de dúvidas existentes na prática clínica que podem estar relacionadas a aspectos básicos da doença ou relacionadas ao manejo da doença e do paciente, como diagnóstico, terapêutica, sobrevida, entre outros. Sendo assim, é fundamental a construção de uma pergunta de pesquisa que defina as evidências necessárias para a resolução da questão clínica, maximize os achados nas bases de dados e evite a realização de buscas desnecessárias. Para a efetividade da pergunta da pesquisa foi utilizado a estratégia PICO, representada pelo acrônimo "P" para paciente, "I" para intervenção, "C" para comparação e "O" para outcomes/resultado ${ }^{75}$. 
Portanto, na presente pesquisa, utilizou-se a estratégica PICO, conforme descrito no Quadro 1: 
Quadro 1 - Estratégia PICO para o desenvolvimento da pergunta da pesquisa da revisão sistemática

\begin{tabular}{|c|l|l|}
\hline ACRÔNIMO & \multicolumn{1}{|c|}{ DEFINIÇÃO } & \multicolumn{1}{|c|}{ DESCRIÇÃO } \\
\hline P & Paciente ou Problema & $\begin{array}{l}\text { Paciente submetido à cirurgia } \\
\text { cardíaca }\end{array}$ \\
\hline I & Intervenção & $\begin{array}{l}\text { Qualquer intervenção não } \\
\text { farmacológica para tratamento da } \\
\text { alteração do padrão do sono }\end{array}$ \\
\hline C & $\begin{array}{l}\text { Controle } \\
\text { Comparação }\end{array}$ & $\begin{array}{l}\text { Cuidado usual (não alteração das } \\
\text { rotinas da unidade) }\end{array}$ \\
\hline $\mathbf{O}$ & Outcome/Resultado & Melhoria do padrão do sono \\
\hline
\end{tabular}

A partir da estratégia PICO acima apresentada, foi formulada a seguinte pergunta: quais são as evidências disponíveis na literatura sobre as mais eficazes intervenções não farmacológicas utilizadas para o tratamento da alteração do padrão do sono em pacientes submetidos à cirurgia cardíaca?

\subsection{LOCALIZAÇÃO E SELEÇÃO DOS ESTUDOS}

Após a etapa inicial, formulação da pergunta da pesquisa, foram definidos os critérios de inclusão e exclusão.

Desta forma, foram incluídos estudos primários desenvolvidos com delineamento de pesquisa que caracteriza evidências fortes, ou seja, os ensaios clínicos controlados randomizados (ECR) classificados como nível de evidência 2, conforme descrito por Melnyk e Fineout-Overholt ${ }^{76}$. Foram considerados estudos com inclusão de pacientes com idade mínima de 18 anos, independentemente do sexo, etnia ou comorbidades, que apresentassem alteração do padrão do sono após serem submetidos à cirurgia de revascularização do miocárdio, cirurgia de correções valvares e de cardiopatias congênitas e/ou cirurgias da aorta. Foram considerados estudos que realizaram a mensuração do padrão do sono sem delimitação da fase pós-cirúrgica e aqueles publicados nos idiomas inglês, português e espanhol. 
Foram excluídos os ECR realizados com pacientes em tratamento clínico e/ou percutâneo de doenças cardíacas e estudos que utilizaram intervenções não farmacológicas associadas às farmacológicas.

A escolha nesta pesquisa pelos estudos experimentais se deve ao fato de serem geralmente utilizados para avaliar terapêuticas e intervenções profiláticas. A PBE considera os estudos experimentais como "padrão ouro" no delineamento das pesquisas clínicas ${ }^{77}$.

Entre os estudos experimentais, o ensaio clínico controlado randomizado é o melhor método de delineamento para os estudos com enfoque etiológico, prognóstico e danos clínicos decorrentes de tratamentos ${ }^{77}$. Consiste na comparação entre grupo experimental (teste) e o grupo controle (teste convencional ou nenhum teste). Nos ensaios clínicos randomizados, os sujeitos da população são distribuídos em grupo experimental e controle de forma aleatória, na oferta ou não de um procedimento, manipulação ou intervenção. Já no ensaio clínico controlado, existe um grupo de pacientes que fornece a base de comparação na avaliação do efeito da intervenção em análise que é dada aos pacientes do grupo experimental ${ }^{78}$.

No processo decisório das práticas em saúde, a PBE propõe uma escala tipológica para classificar a força das evidências a fim de guiar as decisões clínicas. $\mathrm{Na}$ presente RS, optou-se pela utilização das autoras Melnyk e Fineout ${ }^{79}$, que descrevem os tipos e níveis de evidências conforme o Quadro 2: 
Quadro 2 - Sistema de classificação hierárquico da qualidade da evidência

\begin{tabular}{|c|c|}
\hline $\begin{array}{l}\text { Nível de } \\
\text { evidência }\end{array}$ & Tipo de estudo \\
\hline Nível I & $\begin{array}{l}\text { Evidência proveniente de revisões sistemáticas ou metanálise } \\
\text { de ensaios clínicos controlados randomizados (ECR) relevantes } \\
\text { ou de diretrizes clínicas baseadas em revisões sistemáticas de } \\
\text { ECR }\end{array}$ \\
\hline Nível II & Evidência obtida de pelo menos um ECR bem definido \\
\hline Nível III & $\begin{array}{l}\text { Evidência obtida de ensaios clínicos bem delineados sem } \\
\text { randomização }\end{array}$ \\
\hline Nível IV & $\begin{array}{l}\text { Evidência proveniente de estudos de caso-controle ou coorte } \\
\text { bem delineados }\end{array}$ \\
\hline Nível V & $\begin{array}{l}\text { Evidência obtida de revisões sistemáticas de estudos descritivos } \\
\text { e qualitativos }\end{array}$ \\
\hline Nível VI & Evidência de um único estudo descritivo ou qualitativo \\
\hline Nível VII & $\begin{array}{l}\text { Evidência proveniente de opiniões de autoridades e/ou relato de } \\
\text { comitês de especialistas }\end{array}$ \\
\hline
\end{tabular}

Fonte: Melnyk BM, Fineout-Overholt H. Evidence-based practice in nursing and healthcare: a guide to best practice. Philadelphia: Lippincott Williams \& Wilkins; 2011.

$\mathrm{Na}$ sequência do presente estudo, procedeu-se a etapa da busca bibliográfica, que permitiu o levantamento das evidências disponíveis nas bases de dados selecionadas: PubMed/MEDLINE (National Library of Medicine National Institutes of Health), CENTRAL (Cochrane Central Register of Controlled Trials), EMBASE (The Excerpta Medica Database), CINAHL (Cumulative Index to Nursing and Allied Health Literature), Literatura Latino-Americana e do Caribe em Ciências da Saúde (LiLACS), Scopus e PsycINFO.

Os procedimentos realizados seguiram as etapas ${ }^{72,75,80}$ :

- Seleção dos termos de busca: estabelecimento dos descritores controlados indexados, ou seja, terminologias que são padronizadas nas bases de dados eletrônicas. Cada componente da estratégia PICO é classificado como controlado, quando se refere aos descritores de assunto - os conhecidos são o MeSH (Medical Subject Headings), na base de dados 
PubMed/MEDLINE, o DeCS (Descritores em Ciências da Saúde), na base LiLACS e EMTREE (Biomedical Research), na base EMBASE - e nãocontrolado, representado pelas palavras textuais e seus sinônimos.

- Utilização de operadores booleanos (delimitadores): representados pelos termos conectores AND, OR e NOT, permitem realizar combinações entre descritores ou palavras de texto usados nas estratégias de busca, sendo AND uma combinação restritiva, OR uma combinação aditiva e NOT uma combinação excludente.

- Combinação dos componentes da estratégia PICO: considerada a fase final dessa etapa. Após a seleção dos termos de busca e utilização dos operadores booleanos para cada um dos quatro componentes da estratégia $\mathrm{PICO}$, esses devem ser inter-relacionados. Devem-se realizar buscas nas bases de dados utilizando a seguinte estratégia: (P) AND (I) AND (C) AND (O).

A busca pelos estudos primários nesta pesquisa foi realizada via internet nas principais bases de dados da área da saúde e mais especificamente na área da enfermagem, como segue: National Library of Medicine National Institutes of Health (PubMed/MEDLINE), Cochrane Central Register of Controlled Trials (CENTRAL), Literatura Latino-Americana e do Caribe em Ciências da Saúde (LiLACS), Scopus, EMBASE, Cumulative Index to Nursing and Allied Health Literature (CINAHL) e PsycINFO.

Para maximizar a busca e contemplar as evidências disponíveis, utilizamos uma combinação de descritores controlados e não controlados (palavras-chave). Os descritores foram delimitados de acordo com a base de dados em questão, conforme apresentado no Quadro 3. 
Quadro 3 - Descritores controlados segundo base de dados

\begin{tabular}{|c|c|c|}
\hline Bases de dados & Descritores controlados & $\begin{array}{c}\text { Descritores não } \\
\text { controlados }\end{array}$ \\
\hline $\begin{array}{l}\text { MEDLINE } \\
\text { Descritor MeSH } \\
\text { (Medical Subject } \\
\text { Headings) }\end{array}$ & $\begin{array}{l}\text { Cardiac Surgical Procedures } \\
\text { Heart surgery } \\
\text { Heart Injuries/surgery } \\
\text { Heart Diseases/surgery } \\
\text { Sleep Wake Disorders } \\
\text { Sleep Disorders } \\
\text { Circadian Rhythm } \\
\text { Sleep } \\
\text { Treatment outcome } \\
\text { Psychotherapy } \\
\text { Complementary Therapies } \\
\text { Physical Therapy Modalities }\end{array}$ & \\
\hline $\begin{array}{l}\text { CINAHL } \\
\text { Descritor Termo } \\
\text { CINAHL }\end{array}$ & $\begin{array}{l}\text { Cardiac Surgery } \\
\text { Heart surgery } \\
\text { Sleep Disorders }\end{array}$ & \\
\hline $\begin{array}{l}\text { EMBASE } \\
\text { Descritor Emtree }\end{array}$ & $\begin{array}{l}\text { Heart surgery } \\
\text { Sleep Disorders } \\
\text { Sleep } \\
\text { Sleep disturbances } \\
\text { Sleep quality } \\
\text { Music therapy } \\
\text { Relaxation training } \\
\text { Positioning patient } \\
\text { Psychotherapy } \\
\text { Massage }\end{array}$ & \\
\hline
\end{tabular}


Conclusão

\begin{tabular}{|c|c|c|}
\hline Bases de dados & Descritores controlados & $\begin{array}{c}\text { Descritores não } \\
\text { controlados }\end{array}$ \\
\hline $\begin{array}{l}\text { LILACS } \\
\text { Descritor DeCS }\end{array}$ & Sono & $\begin{array}{l}\text { Cardiac } \\
\text { Coração } \\
\text { Heart } \\
\text { Surgery } \\
\text { Cirurgia }\end{array}$ \\
\hline $\begin{array}{l}\text { Psyclnfo } \\
\text { Descritor APA } \\
\text { Thesaurus }\end{array}$ & $\begin{array}{l}\text { Heart surgery } \\
\text { Sleep Disorders } \\
\text { Sleep } \\
\text { Intervention } \\
\text { Music therapy } \\
\text { Relaxation } \\
\text { Relaxation therapy } \\
\text { Psychotherapy } \\
\text { Massage }\end{array}$ & \\
\hline $\begin{array}{l}\text { COCHRANE } \\
\text { Descritor MeSH } \\
\text { (Medical Subject } \\
\text { Headings) }\end{array}$ & $\begin{array}{l}\text { Cardiac Surgery } \\
\text { Heart surgery } \\
\text { Sleep Disorders } \\
\text { Sleep disturbances } \\
\text { Sleep quality } \\
\text { Relaxation training }\end{array}$ & \\
\hline SCOPUS & & $\begin{array}{l}\text { Cardiac Surgery } \\
\text { Sleep Disorders } \\
\text { Cardiac } \\
\text { Heart } \\
\text { Surgical } \\
\text { Surgery } \\
\text { Intervention* } \\
\text { Clinical trial* } \\
\text { Non-pharmacolo* }\end{array}$ \\
\hline
\end{tabular}


Na estratégia de busca, não foi estabelecido limite temporal para a data de publicação dos estudos com o intuito de não diminuir a sensibilidade da busca, visto se tratar de um assunto ainda pouco investigado.

Diferentes estratégias de busca foram realizadas em cada base de dados, uma vez que as bases possuem distintos delineamentos para a busca. A busca foi realizada nos meses de junho e julho de 2016.

Realizou-se uma busca na literatura "cinzenta" utilizando as seguintes bases de dados: Proquest Dissertations and Theses, Biblioteca Digital de Teses e Dissertações da Universidade de São Paulo, Evidence-Informed Policy Network (EVIPNet), Observatório da Produção Intelectual da Faculdade de Medicina da Universidade de São Paulo, Registro Brasileiro de Ensaios Clínicos e ClinicalTrials.gov. As estratégias de busca conforme bases de dados utilizadas para o desenvolvimento da RS estão descritas no Quadro 4.

Também foi realizada uma busca manual nas referências bibliográficas dos estudos primários encontrados, com o intuito de verificar a existência de eventuais estudos não recuperados pela estratégia de busca proposta. 
Quadro 4 - Estratégias de busca segundo bases de dados

\begin{tabular}{|c|c|}
\hline Base de Dados & Estratégia de Busca \\
\hline PUBMED & 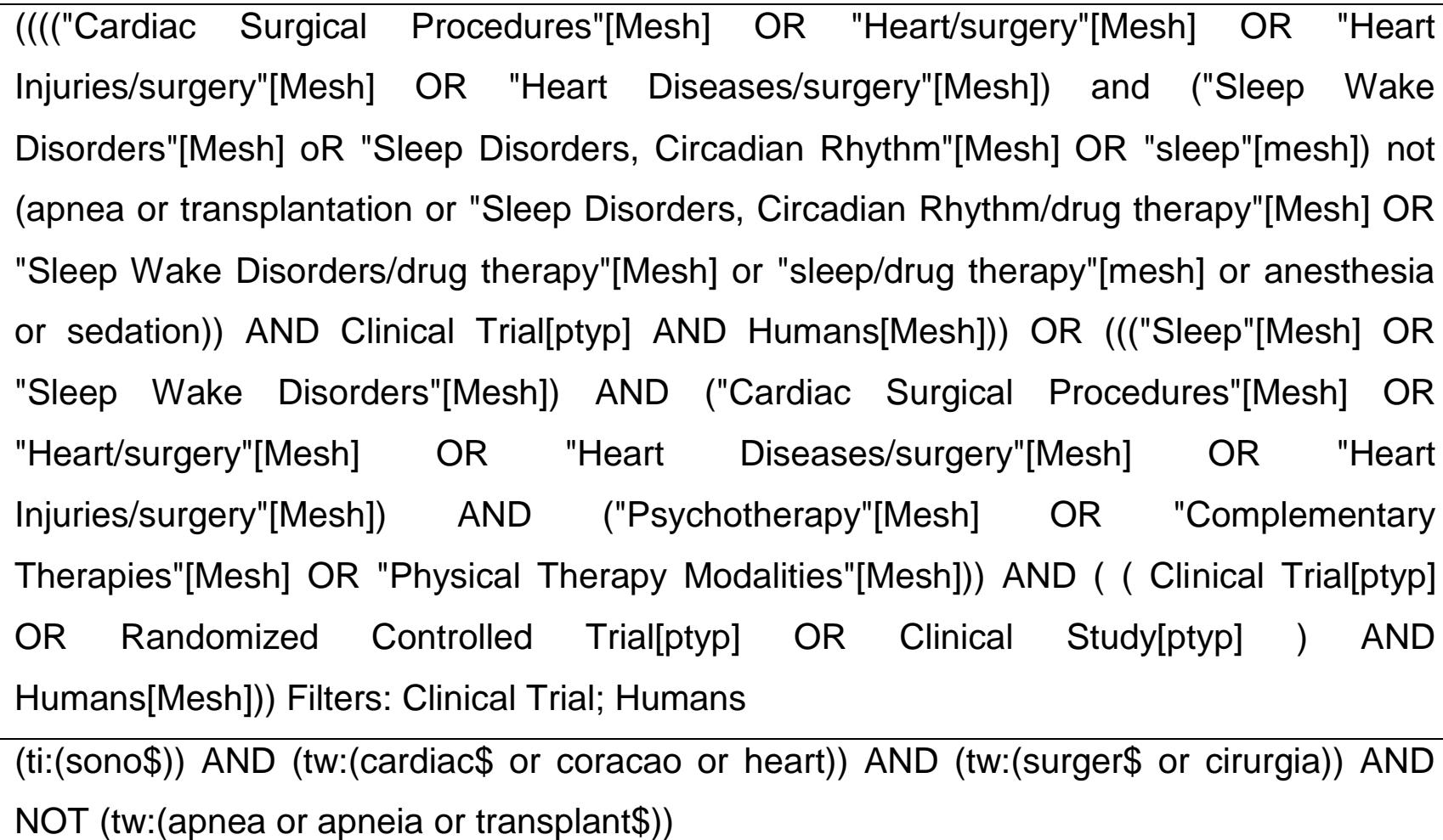 \\
\hline
\end{tabular}




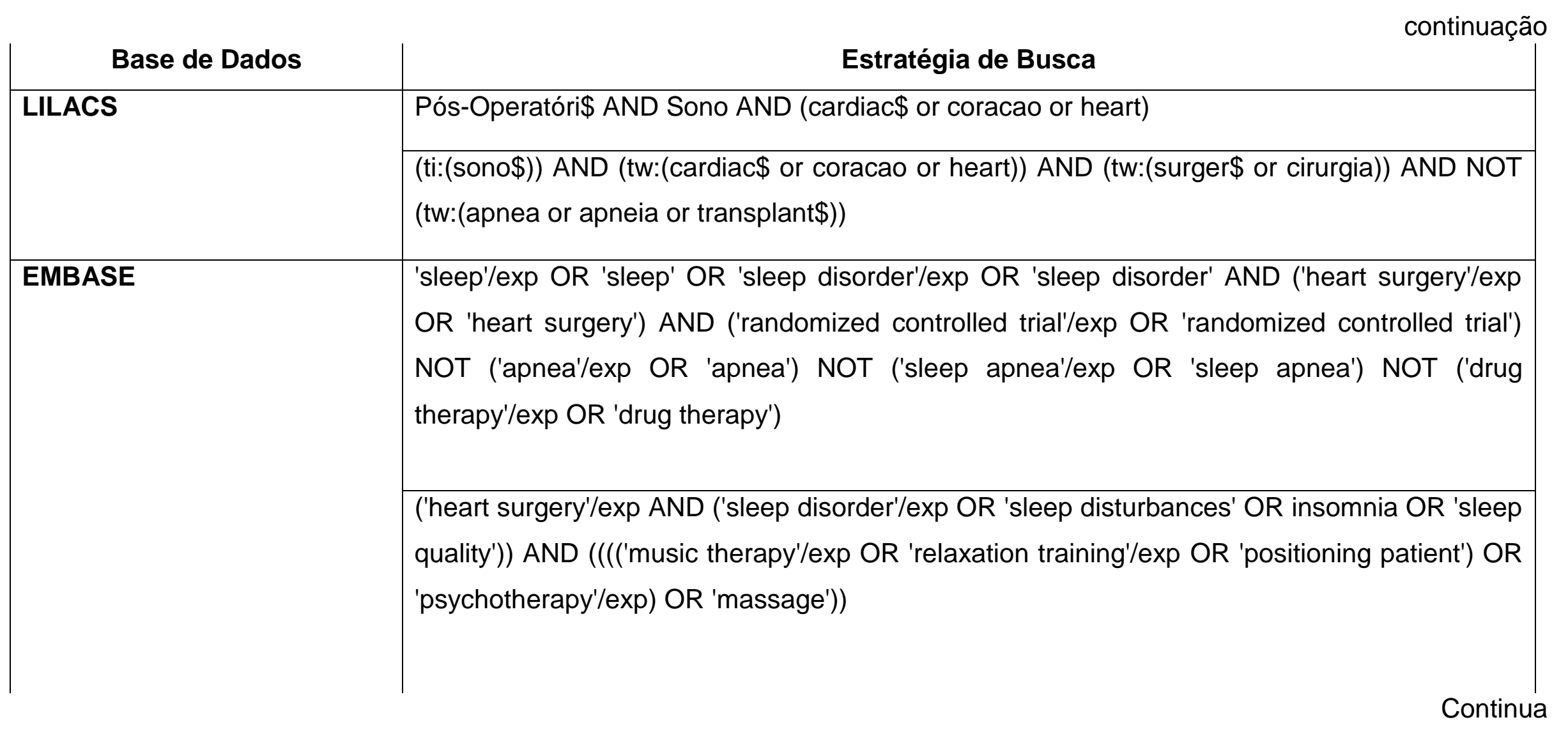




\begin{tabular}{|c|c|}
\hline Base de Dados & Estratégia de Busca \\
\hline SCOPUS & 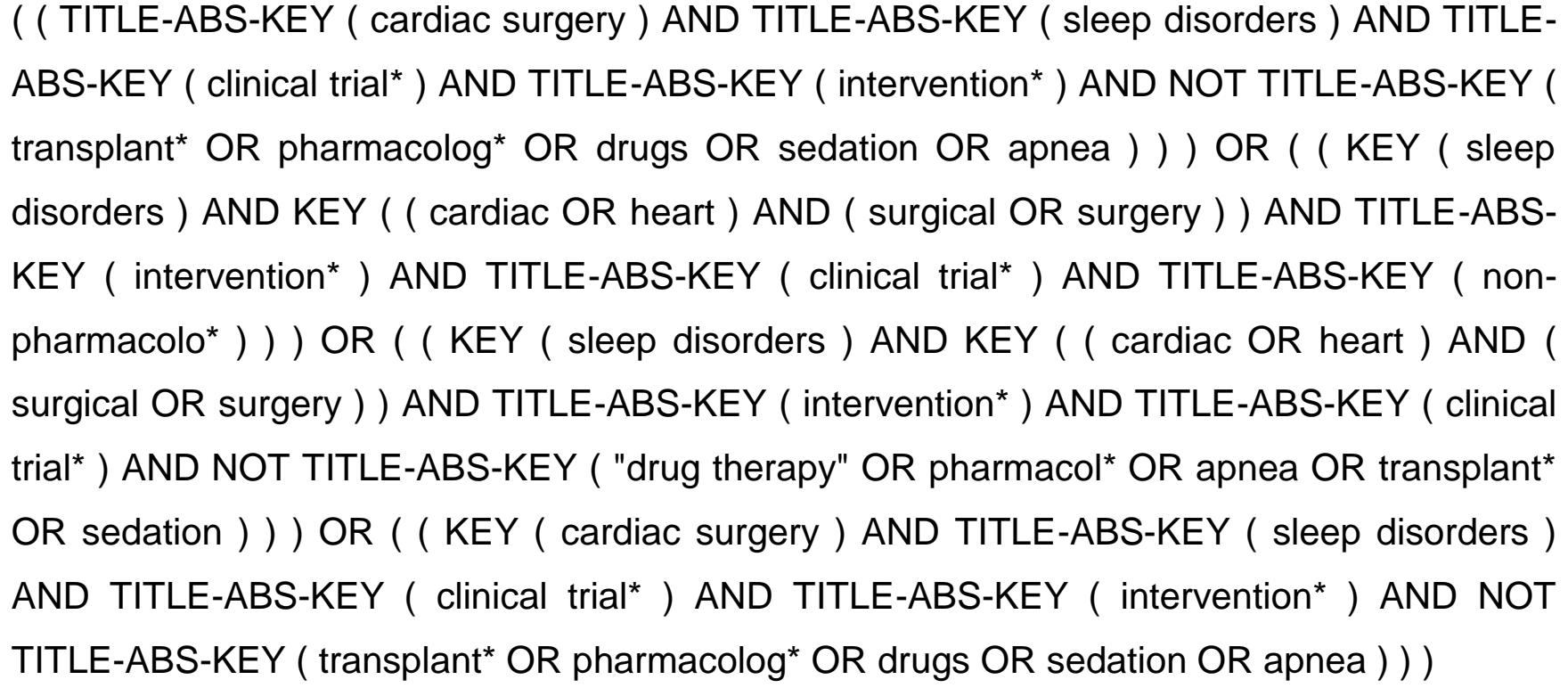 \\
\hline CINAHL & $\begin{array}{l}\text { (cardiac surgery OR heart surgery) and sleep disorders not (transplantation or transplant or } \\
\text { drug therapy or sedation or apnea) }\end{array}$ \\
\hline COCHRANE & $\begin{array}{l}\text { '(("sleep disorders" OR "sleep disturbances OR "sleep quality”) AND ("massage” OR } \\
\text { "relaxation training" OR "patient position”) AND ("cardiac surgery" OR "heart surgery”)) in Title, } \\
\text { Abstract, Keywords in Trials' }\end{array}$ \\
\hline Psyclnfo & $\begin{array}{l}\text { \{Heart Surgery\} AND \{Intervention }\} \text { AND \{Massage }\} \text { AND \{Music Therapy }\} \text { AND } \\
\text { \{Psychotherapy\} AND \{Relaxation\} AND }\{\text { Relaxation Therapy\} AND }\{\text { Sleep }\} \text { AND \{Sleep } \\
\text { Disorders }\end{array}$ \\
\hline
\end{tabular}




\begin{tabular}{|l|l|}
\multicolumn{1}{|c|}{ Base de Dados } & \multicolumn{1}{c|}{ Estratégia de Busca } \\
\hline $\begin{array}{l}\text { Biblioteca Digital de Teses e } \\
\text { Dissertações da Universidade de } \\
\text { São Paulo }\end{array}$ & "sono" e "distúrbios do sono" e "cirurgia cardíaca" \\
\hline \multirow{2}{*}{$\begin{array}{l}\text { Evidence-Informed Policy } \\
\text { Network (EVIPNet) }\end{array}$} & mh:(sono) AND mh:(distúrbio do sono) AND mh:(cirurgia cardíaca) \\
\cline { 2 - 3 } & mh:(sleep) AND mh:(sleep disorders) AND mh:(cardiac surgery) \\
\hline $\begin{array}{l}\text { Observatório da Produção } \\
\text { Intelectual da Faculdade de } \\
\text { Medicina da Universidade de São } \\
\text { Paulo }\end{array}$ & Sleep AND "cardiac surgery" \\
\cline { 2 - 3 } & Sleep AND "heart surgery" \\
\hline $\begin{array}{l}\text { Registro Brasileiro de Ensaios } \\
\text { Clínicos }\end{array}$ & $\begin{array}{l}\text { Sono AND cirurgia cardiac } \\
\text { Sleep AND cardiac surgery } \\
\text { Sleep AND heart surgery }\end{array}$ \\
\hline ClinicalTrials.gov & "sleep" AND "cardiac surgery" \\
\hline
\end{tabular}




\subsection{AVALIAÇÃO CRÍTICA DOS ESTUDOS}

A fim de assegurar a qualidade desta etapa e evitar vieses de seleção, foi realizada a checagem de todos os estudos por pelo menos dois revisores de forma independente.

A avaliação de inclusão ou não do estudo na RS foi realizada com base na leitura do título e resumo. A discordância encontrada entre os dois revisores foi resolvida com a participação de um terceiro revisor. Os artigos selecionados foram avaliados em texto completo para garantir que os critérios de inclusão fossem atendidos. O resultado inicial das buscas pelos estudos primários identificou 280 artigos nas bases de dados selecionadas.

Os artigos repetidos nas bases de dados e entre os selecionados foram diagnosticados e foi realizada a seleção definitiva. Os números de artigos encontrados e excluídos de cada base de dados e o fluxograma sobre o desenvolvimento da busca estão ilustrados na Tabela 1 e Figura 1.

Tabela 1 - Número de estudos primários encontrados e potencial de inclusão de acordo com as bases de dados

\begin{tabular}{|c|c|c|}
\hline Base de dados & $\begin{array}{l}\text { Estudo primário } \\
\text { encontrado }\end{array}$ & $\begin{array}{l}\text { Estudo primário } \\
\text { potencial de } \\
\text { inclusão }\end{array}$ \\
\hline PUBMED & 126 & 6 \\
\hline LILACS & 9 & 1 \\
\hline EMBASE & 71 & 11 \\
\hline SCOPUS & 10 & 0 \\
\hline CINAHL & 9 & 4 \\
\hline COCHRANE & 6 & 2 \\
\hline Psyclnfo & 0 & 0 \\
\hline BDTD & 1 & 0 \\
\hline OPI & 26 & 0 \\
\hline Registro Brasileiro de Ensaios & 0 & 0 \\
\hline \multicolumn{3}{|l|}{ Clínicos } \\
\hline Clinical Trials & 22 & 1 \\
\hline EVIPNet & 0 & 0 \\
\hline Total & 280 & 25 \\
\hline
\end{tabular}


Não foram encontrados estudos nas bases de dados Psyclnfo, Registro Brasileiro de Ensaios Clínicos e EVIPNet que atendessem aos critérios de inclusão.

Os motivos pelos quais ocorreu a exclusão dos estudos primários incluíram considerar que o método não contemplava o ensaio clínico randomizado, não mensuração da qualidade do sono, ausência de intervenção não farmacológica para promoção do sono e avaliação de outros pacientes e não aqueles em pós-operatório de cirurgia cardíaca.

Treze estudos foram incluídos para a etapa de leitura do texto completo. Dos 13 estudos selecionados, oito estavam disponíveis eletronicamente nas bases de dados, três foram acessados por meio de contato com bibliotecas nacionais e dois em bibliotecas internacionais.

Nesta seleção de 13 estudos, constatou-se divergência entre os dois revisores, a qual foi solucionada com a participação do terceiro revisor. Entre as divergências, estava presente um estudo com pacientes cuja revascularização se deu pelo método percutâneo, portanto excluído, e outros dois estudos que avaliaram a recuperação cardíaca cirúrgica dos pacientes, sem relatar, no entanto, o domínio sono como uma variável de análise. A amostra final da RS foi composta por 10 estudos que avaliaram a eficácia de uma intervenção não farmacológica em pacientes com alteração do padrão do sono após cirurgia cardíaca.

A extração de dados dos 10 estudos primários selecionados foi realizada de forma independente pelos dois revisores. Para tal procedimento, foi utilizado 0 instrumento elaborado por Ursi, ${ }^{81}$ conforme anexo $\mathrm{A}$, o qual foi submetido ao processo de validação pelo autor e contempla as seguintes informações:

$\checkmark$ Identificação do estudo - título do artigo, periódico, autores, ano de publicação, país de origem.

$\checkmark$ Características metodológicas do estudo - objetivo, tamanho da amostra, critérios de inclusão e exclusão, tipo de intervenção, tratamento dos dados, resultados evidenciados, conclusões.

$\checkmark$ Avaliação do rigor metodológico - descrição da trajetória metodológica, se a análise estatística foi apropriada para responder à pergunta de pesquisa, se apresenta recomendações para a prática e as limitações do estudo. 
A segunda etapa, leitura do texto completo dos estudos elegíveis, foi realizada por ambos os revisores e abarcou o preenchimento do instrumento. Todos os dados extraídos foram conferidos e confirmados. As questões em que houve divergências foram analisadas novamente e discutidas entre os revisores, a fim de que estabelecessem um consenso.

Houve necessidade da opinião do terceiro avaliador após a leitura do texto completo dos estudos para realizar possíveis exclusões com segurança. Foram excluídos três estudos: um com delineamento de estudo quase experimental ${ }^{82}$, um que utiliza mixed methods (estudo quali-quantitativo) ${ }^{83}$ e outro por não ser ensaio clínico randomizado ${ }^{84}$.

Figura 1 - Fluxograma utilizado na seleção dos estudos da RS

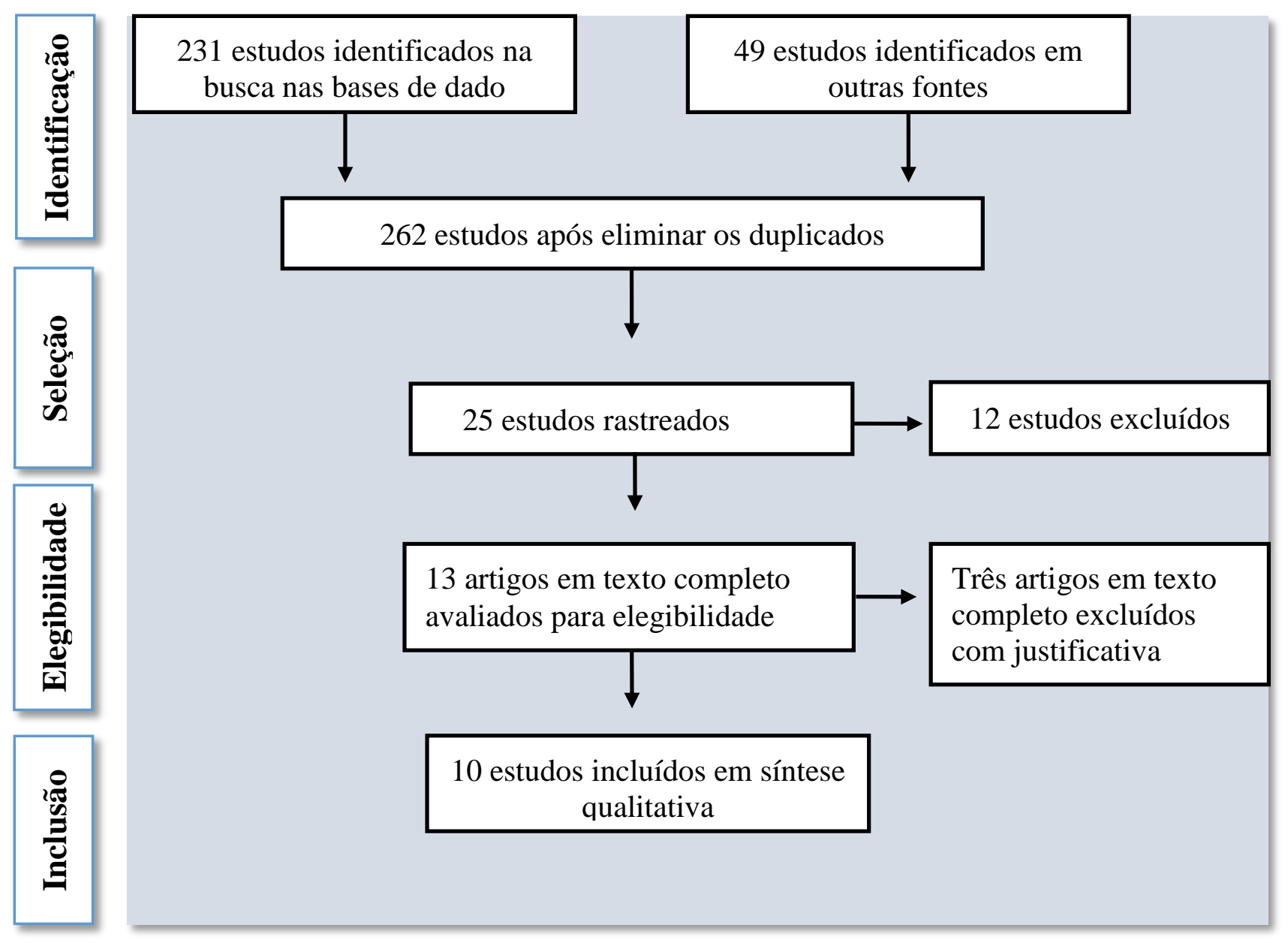

Fluxograma baseado no PRISMA $2009^{85}$. 


\subsection{ANÁLISE, INTERPRETAÇÃO E APRESENTAÇÃO DOS RESULTADOS DOS ESTUDOS}

A qualidade dos estudos individuais ou primários é fundamental para se considerar a relevância dos resultados. Estudos clínicos podem ser deturpados na aleatorização (randomização), no mascaramento do tratamento alocado e na análise. Os estudos devem ser considerados por classificação e ordenamento por qualidade $^{86}$. A qualidade de um estudo inclui aspectos como delineamento da pesquisa, construção das hipóteses, população do estudo, tamanho da amostra, método e seleção dos participantes, definição das variáveis, instrumento de coleta e procedimento de controle e qualidade das medidas ${ }^{87}$.

Para a avaliação da qualidade metodológica dos ensaios clínicos randomizados controlados, utilizou-se o escore de Jadad et al. ${ }^{88}$. O instrumento contém três itens de avaliação na forma de questão, a saber:

1) O ensaio clínico é descrito como randomizado?

2) O ensaio clínico é descrito como duplo cego?

3) No ensaio clínico, há descrição das saídas e abandonos dos participantes do estudo?

O revisor responde sim ou não para cada questão. Para cada resposta sim, um ponto é atribuído ao escore. Se a reposta é não, o valor é zero. No final dessa etapa da avaliação, o escore máximo do ensaio clínico será três, visto que há três questões.

A seguir, o revisor acrescenta um ponto na primeira questão, quando o método de randomização foi descrito e é apropriado, e outro ponto na segunda questão, quando o método de duplo cego foi descrito e é apropriado. O revisor subtrai um ponto da primeira questão, quando o método de randomização foi descrito e é inapropriado, e outro ponto da segunda questão, quando o método de duplo cego foi descrito e é inapropriado. O escore máximo obtido na avaliação do ensaio clínico é cinco ${ }^{88}$.

A síntese dos resultados evidenciados da RS foi realizada na forma descritiva para possibilitar a compreensão de todos os artigos incluídos e para fornecer 
informações detalhadas de cada estudo primário, tais como tamanho da amostra, tipo de intervenção, tempo de pós-operatório, método de mensuração e resultados.

De acordo com a intervenção testada pelos autores dos estudos primários incluídos, foram realizados agrupamentos categóricos. 
5 RESULTADOS 


\subsection{CARACTERÍSTICAS DOS ESTUDOS PRIMÁRIOS}

A amostra final da RS foi composta por dez estudos primários. As principais características dos artigos selecionados estão descritas no Quadro 5.

Os dez estudos primários selecionados foram publicados no idioma inglês. Em relação à origem dos periódicos, quatro foram desenvolvidos nos Estados Unidos da América, dois na China, um no Irã, um na Turquia, um na Suécia e um no Brasil. Dos estudos incluídos, $60 \%$ foram publicados nos últimos cinco anos, 20\% entre os anos 2007 e 2010 e outros $20 \%$ na década de 1990 . Verifica-se que 50\% dos estudos foram publicados em revista científica de enfermagem; os demais foram publicados predominantemente em periódicos na área médica.

Todos os estudos incluídos foram classificados como nível 2 de evidência segundo Melnyk Pyramid ${ }^{79}$. 
Quadro 5 - Caracterização dos estudos primários incluídos na revisão sistemática, segundo título, autores, periódico, origem e ano de publicação

\begin{tabular}{|c|c|c|c|c|c|c|}
\hline $\begin{array}{l}\text { Número } \\
\text { do Estudo }\end{array}$ & Título & Autores & Periódico & $\begin{array}{l}\text { Origem do } \\
\text { Periódico }\end{array}$ & Idioma & $\begin{array}{c}\text { Ano de } \\
\text { publicação }\end{array}$ \\
\hline 1 & $\begin{array}{l}\text { The effects of a symptom } \\
\text { management intervention on } \\
\text { symptom evaluation, physical } \\
\text { functioning, and physical activity for } \\
\text { women after coronary artery bypass } \\
\text { surgery }\end{array}$ & 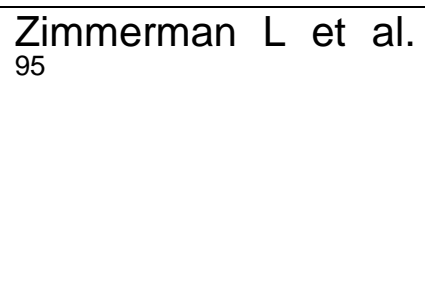 & $\begin{array}{l}\text { Journal of } \\
\text { Cardiovascular } \\
\text { Nursing }\end{array}$ & $\begin{array}{l}\text { Estados } \\
\text { Unidos }\end{array}$ & Inglês & 2007 \\
\hline 2 & $\begin{array}{l}\text { A preoperative education } \\
\text { intervention to reduce anxiety and } \\
\text { improve recovery among Chinese } \\
\text { cardiac patients: a randomized } \\
\text { controlled trial }\end{array}$ & Guo $P$ et al. ${ }^{96}$ & $\begin{array}{l}\text { International } \\
\text { Journal of Nursing } \\
\text { Studies }\end{array}$ & China & Inglês & 2012 \\
\hline 3 & $\begin{array}{l}\text { Effects of massage therapy on sleep } \\
\text { quality after coronary artery bypass } \\
\text { graft surgery }\end{array}$ & Nerbass FB et al. ${ }^{89}$ & Clinics & Brasil & Inglês & 2010 \\
\hline 4 & $\begin{array}{l}\text { Effects of earplugs and eye masks } \\
\text { combined with relaxing musico os } \\
\text { sleep, melatonina and cortisol levels } \\
\text { in ICU patients: a randomized } \\
\text { controlled trial }\end{array}$ & Hu RF et al. ${ }^{66}$ & Critical Care & China & Inglês & 2015 \\
\hline 5 & $\begin{array}{l}\text { Evaluation of an individualised } \\
\text { programme to promote self-care in } \\
\text { sleep-activity in patients with } \\
\text { coronary artery disease: a } \\
\text { randomized intervention study }\end{array}$ & 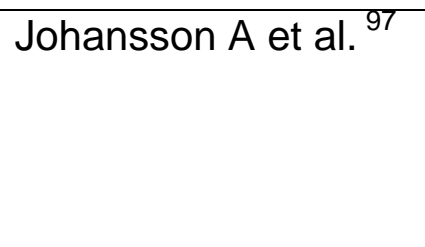 & $\begin{array}{l}\text { Journal of Clinical } \\
\text { Nursing }\end{array}$ & Suécia & Inglês & 2014 \\
\hline
\end{tabular}




\begin{tabular}{|c|c|c|c|c|c|c|}
\hline $\begin{array}{l}\text { Número } \\
\text { do Estudo }\end{array}$ & Título & Autores & Periódico & $\begin{array}{l}\text { Origem do } \\
\text { Periódico }\end{array}$ & Idioma & $\begin{array}{c}\text { Ano de } \\
\text { publicação }\end{array}$ \\
\hline 6 & $\begin{array}{l}\text { The effects of posture and relaxation } \\
\text { training on sleep, dyspnea, pain and, } \\
\text { quality of life in the short-term after } \\
\text { cardiac surgery: a pilot study }\end{array}$ & Akinci B et al. ${ }^{90}$ & $\begin{array}{l}\text { Turk Gogus Kalp } \\
\text { Dama }\end{array}$ & Turquia & Inglês & 2016 \\
\hline 7 & $\begin{array}{l}\text { Poor sleep quality in patients after } \\
\text { coronary artery bypass graft surgery: } \\
\text { an intervention study using the } \\
\text { PRECEDE-PROCEED Model }\end{array}$ & Ranjbaran S et al. ${ }^{91}$ & $\begin{array}{l}\text { The Journal of } \\
\text { Tehran University } \\
\text { Heart Center }\end{array}$ & Irã & Inglês & 2015 \\
\hline 8 & $\begin{array}{l}\text { The effects of guided imagery on } \\
\text { sleep and } \\
\text { inflammatory response in cardiac } \\
\text { surgery: a pilot randomized } \\
\text { controlled trial }\end{array}$ & Casida JM et al. ${ }^{92}$ & $\begin{array}{l}\text { The Journal of } \\
\text { Cardiovascular } \\
\text { Surgery }\end{array}$ & $\begin{array}{l}\text { Estados } \\
\text { Unidos }\end{array}$ & Inglês & 2013 \\
\hline 9 & $\begin{array}{l}\text { The effects of music interventions on } \\
\text { postoperative pain and sleep in } \\
\text { coronary artery bypass graft (CABG) } \\
\text { patients }\end{array}$ & 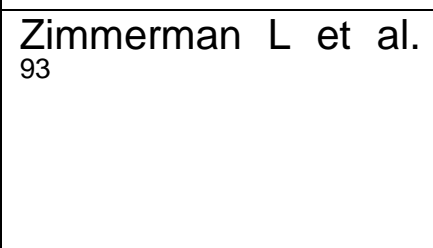 & $\begin{array}{lr}\text { Scholary } & \text { Inquiry } \\
\text { for } & \text { Nursing } \\
\text { Pratice: } & \text { an } \\
\text { International } \\
\text { Journal }\end{array}$ & $\begin{array}{l}\text { Estados } \\
\text { Unidos }\end{array}$ & Inglês & 1996 \\
\hline 10 & $\begin{array}{l}\text { The effects of ocean sounds on } \\
\text { sleep after coronary artery bypass } \\
\text { graft surgery }\end{array}$ & Williamson $\mathrm{JW}^{94}$ & $\begin{array}{l}\text { American Journal } \\
\text { of Critical Care }\end{array}$ & $\begin{array}{l}\text { Estados } \\
\text { Unidos }\end{array}$ & Inglês & 1992 \\
\hline
\end{tabular}




\subsection{CARACTERÍSTICAS METODOLÓGICAS DOS ESTUDOS PRIMÁRIOS}

Como mencionado anteriormente, foi adotado o escore de Jadad et al. ${ }^{88}$ para a avaliação da qualidade metodológica dos ensaios clínicos controlados randomizados.

A qualidade metodológica dos estudos primários da RS foi apresentada no Quadro 6, sendo escore de Jadad menor ou igual a dois, qualidade baixa; escore igual a três, qualidade moderada; e escore maior ou igual a quatro, qualidade alta. Houve considerável variação no escore de Jadad dos estudos incluídos na RS. Foram considerados de baixa qualidade $50 \%$ dos ensaios clínicos e os outros $50 \%$ de moderada qualidade. Observa-se que não foi encontrado estudo de alta qualidade metodológica. 
Quadro 6 - Distribuição dos estudos primários conforme avaliação pelo Escore de Jadad et al. ${ }^{88}$

\begin{tabular}{|c|c|c|c|c|c|c|}
\hline $\begin{array}{l}\text { Número do } \\
\text { Estudo }\end{array}$ & Estudo & Randomizado & $\begin{array}{c}\text { Método de } \\
\text { randomização descrito } \\
\text { e apropriado }\end{array}$ & $\begin{array}{l}\text { Duplo- } \\
\text { cego }\end{array}$ & $\begin{array}{l}\text { Descrito saídas e } \\
\text { abandonos dos } \\
\text { participantes }\end{array}$ & $\begin{array}{l}\text { Escore } \\
\text { Jadad }\end{array}$ \\
\hline 1 & Zimmerman L et al. ${ }^{95}$ & Sim & Não & Não & Sim & 2 \\
\hline 2 & Guo $P$ et al. ${ }^{96}$ & Sim & Sim & Não & Sim & 3 \\
\hline 3 & Nerbass FB et al. ${ }^{89}$ & Sim & Não & Não & Sim & 2 \\
\hline 4 & Hu RF et al. ${ }^{66}$ & Sim & Sim & Não & Sim & 3 \\
\hline 5 & Johansson $A$ et al. ${ }^{97}$ & Sim & Não & Não & Sim & 2 \\
\hline 6 & Akinci B et al. ${ }^{90}$ & Sim & Sim & Não & Sim & 3 \\
\hline 7 & Ranjbaran S et al. ${ }^{91}$ & Sim & Não & Não & Não & 1 \\
\hline 8 & Casida JM et al. ${ }^{92}$ & Sim & Sim & Não & Sim & 3 \\
\hline 9 & Zimmerman L et al. ${ }^{93}$ & Sim & Não & Não & Não & 1 \\
\hline 10 & Williamson JW ${ }^{94}$ & Sim & Sim & Não & Sim & 3 \\
\hline
\end{tabular}




\subsection{SÍNTESE DOS ESTUDOS PRIMÁRIOS SEGUNDO INTERVENÇÃO TESTADA}

A maioria dos estudos testou intervenções que promovem o relaxamento e consequentemente melhoram a qualidade do sono, porém diferentes métodos foram utilizados para o alcançar do objetivo proposto. As intervenções não farmacológicas que foram avaliadas pelos autores dos estudos incluíram gerenciamento de sintomas no período pós-operatório, educação pré-operatória, massagem, máscara de olhos e tampões de ouvidos, educação e relaxamento, treino de postura e relaxamento muscular, programa de imagem guiada e música.

De acordo com a intervenção realizada, os estudos foram divididos em três categorias gerais: técnicas de relaxamento, dispositivos ou equipamentos para minimizar a interrupção do sono e/ou induzir ao sono e as estratégias educacionais. Não obstante esta divisão em categorias ser clara, cada estudo se enquadra em mais de uma delas. Para fins de categorização, foi considerada a característica mais marcante em cada estudo.

Dos 10 estudos primários que compõem a RS, três foram categorizados como relaxamento, como mostram os Quadros 7, 8 e 9. 
Quadro 7 - Síntese do estudo 3 categorizado como relaxamento

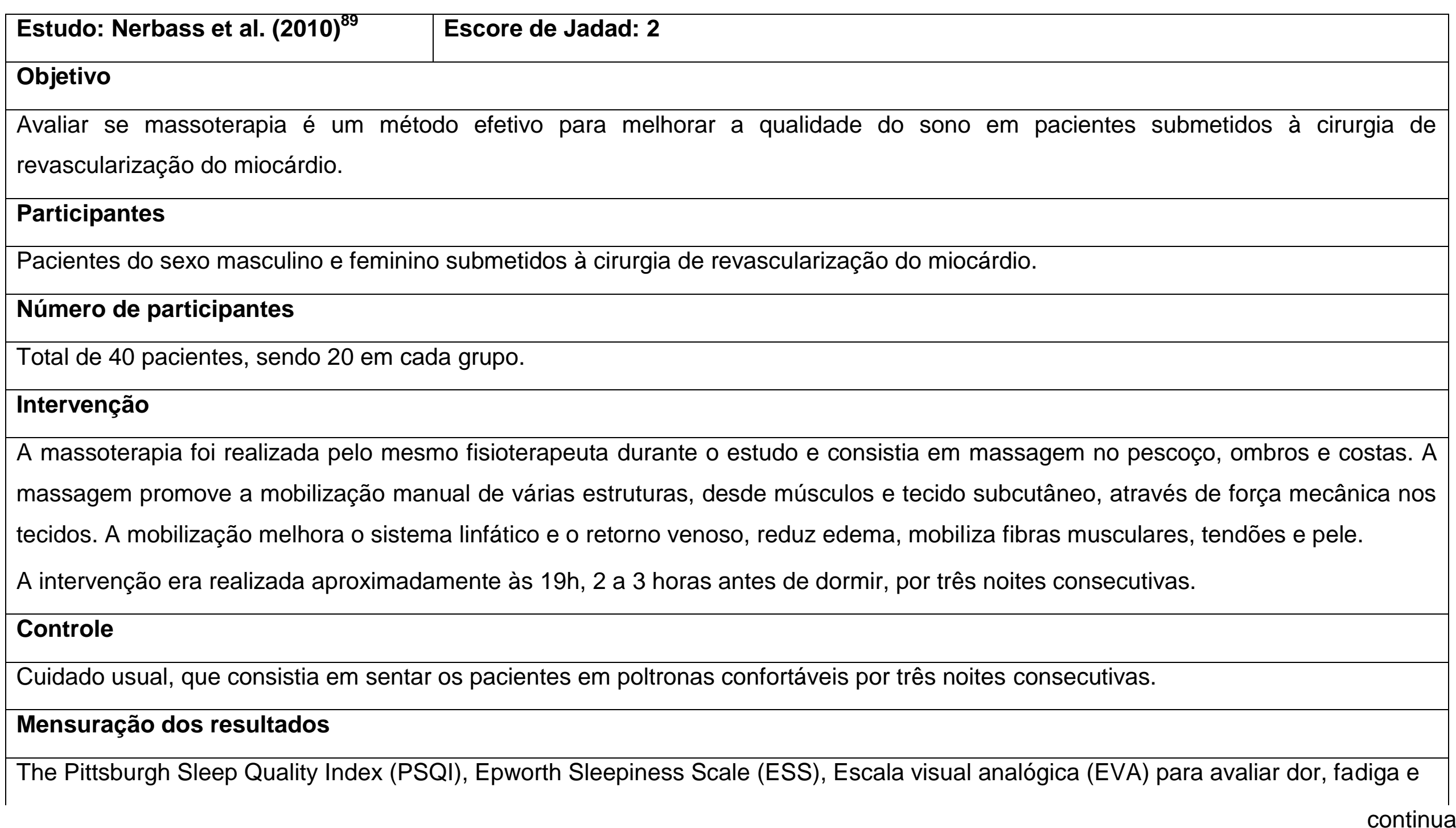


sono, Diário do sono e Berlin Questionnaire para classificar o risco do paciente em desenvolver apneia obstrutiva do sono.

\section{Resultados e Conclusões}

Ao longo do estudo, todos os pacientes preenchiam diariamente o diário do sono e foram avaliados quanto aos níveis de dor e fadiga e qualidade do sono na manhã seguinte da intervenção.

O tempo total de sono, obtido através do diário do sono, foi similar entre os pacientes de ambos os grupos do estudo.

Não houve diferença significativa entre os grupos no pré-operatório com relação aos valores obtidos nas escalas de PSQI e ESS.

Os participantes do grupo intervenção obtiveram maior eficiência do sono avaliada pela EVA em comparação aos do grupo controle.

Os escores de dor durante o período pós-operatório apresentaram redução significativa entre os participantes de ambos os grupos.

Com relação à fadiga, os pacientes do grupo intervenção mostraram menores escores em comparação aos do grupo controle.

Os resultados do estudo mostram que massoterapia é um método efetivo para melhorar a qualidade do sono e reduzir a fadiga dos pacientes. Sendo assim, a intervenção contribui para a recuperação do paciente em pós-operatório de cirurgia cardíaca. 
Quadro 8 - Síntese do estudo 6 categorizado como relaxamento

\begin{tabular}{|c|c|}
\hline Estudo: Akinci et al. (2016) & Escore de Jadad: 3 \\
\hline \multicolumn{2}{|l|}{ Objetivo } \\
\hline \multicolumn{2}{|c|}{$\begin{array}{l}\text { Avaliar os efeitos a curto prazo de um programa de treinamento de postura e relaxamento sobre qualidade do sono, sonolência diurna, } \\
\text { dispneia, qualidade de vida e dor em pacientes após cirurgia cardíaca. }\end{array}$} \\
\hline \multicolumn{2}{|l|}{ Participantes } \\
\hline \multicolumn{2}{|c|}{$\begin{array}{l}\text { Pacientes do sexo masculino e feminino submetidos à cirurgia de revascularização do miocárdio, correções valvares, e } \\
\text { revascularização do miocárdio e correção valvar em um mesmo procedimento. }\end{array}$} \\
\hline \multicolumn{2}{|l|}{ Número de participantes } \\
\hline \multicolumn{2}{|c|}{ Total de 24 pacientes, sendo 12 em cada grupo. } \\
\hline \multicolumn{2}{|l|}{ Intervenção } \\
\hline \multicolumn{2}{|c|}{$\begin{array}{l}\text { O programa de treinamento foi dividido em três etapas: a) fisioterapia respiratória - técnicas de tosse, treinamento com espirômetro e } \\
\text { técnicas para drenagem de secreção; b) mobilização progressiva precoce - aumento gradual da distância percorrida na caminhada; c) } \\
\text { treinamento de postura e relaxamento (PRT) - mobilidade da região torácica e cervical, extensão do joelho, extensão e flexão da } \\
\text { extremidade distal e exercícios de respiração profunda. }\end{array}$} \\
\hline Controle & \\
\hline
\end{tabular}




\section{Mensuração dos resultados}

PSQI, ESS, Modified Medical Research Council Dyspnea Scale para avaliar dispneia, Euro Quality of Life-5D para avaliar qualidade de vida e EVA para mensurar a dor.

\section{Resultados e Conclusões}

Em ambos os grupos do estudo, a intervenção foi realizada duas vezes ao dia, em sessões de 30 minutos, por duas semanas. Na primeira semana, o treinamento foi realizado uma vez ao dia sob a supervisão do fisioterapeuta e outra vez sem a supervisão.

Todos os pacientes foram orientados a realizar a segunda sessão do dia antes de dormir. Após a alta hospitalar, os pacientes continuaram com o programa de reabilitação em casa sem a supervisão por uma semana.

As avaliações de todos os pacientes foram realizadas em dois momentos, antes e duas semanas após a cirurgia. Os pacientes foram orientados a preencher o PSQI entregue no pré-operatório considerando os seus hábitos de sono nos 30 dias anteriores à cirurgia.

Os participantes do grupo intervenção apresentaram melhora significativa após o programa de treinamento em comparação aos do grupo controle em termos de escore total do PSQI, uso de medicamentos para dormir e qualidade de vida. A qualidade do sono percebida pelo paciente e o escore de dor foram significativamente piores entre os pacientes do grupo controle.

Os resultados do estudo sugerem que adicionar o PRT ao protocolo de reabilitação usual propiciou mais benefícios na manutenção da qualidade do sono percebida pelo paciente, redução nos distúrbios do sono e uso de medicamentos para dormir em pacientes submetidos à cirurgia cardíaca. Além disso, o PRT é mais efetivo em aliviar a dispneia e tem um efeito preventivo sobre a percepção da dor após a cirurgia cardíaca.

A intervenção ainda possui outras vantagens observadas nesse estudo, como aumentar a mobilidade e melhorar a recuperação dos pacientes, ser um método seguro e bem tolerado e não depender de equipamentos e dispositivos. 
Quadro 9 - Síntese do estudo 7 categorizado como relaxamento

\begin{tabular}{|c|c|}
\hline Estudo: Ranjbaran et al. (2015) ${ }^{91}$ & Escore de Jadad: 1 \\
\hline \multicolumn{2}{|l|}{ Objetivo } \\
\hline \multicolumn{2}{|c|}{$\begin{array}{l}\text { Determinar o efeito de uma intervenção educativa baseada no modelo PRECED-PROCEED sobre a qualidade do sono de pacientes } \\
\text { submetidos à cirurgia de revascularização do miocárdio. }\end{array}$} \\
\hline \multicolumn{2}{|l|}{ Participantes } \\
\hline \multicolumn{2}{|c|}{ Pacientes do sexo masculino e feminino submetidos à cirurgia de revascularização do miocárdio. } \\
\hline \multicolumn{2}{|l|}{ Número de participantes } \\
\hline \multicolumn{2}{|c|}{ Total de 100 pacientes, 50 em cada grupo. } \\
\hline \multicolumn{2}{|c|}{ Intervenção } \\
\hline \multicolumn{2}{|c|}{$\begin{array}{l}\text { Cuidado usual + intervenção baseada no modelo PRECED-PROCEED, terapia de relaxamento muscular progressivo (PMR). } \\
\text { A intervenção foi realizada em oito sessões, sendo uma sessão por semana, com duração de } 45 \text { a } 60 \text { minutos. A proposta da primeira } \\
\text { sessão foi aumentar o conhecimento dos pacientes sobre os problemas do sono após a cirurgia de revascularização do miocárdio. Um } \\
\text { folheto informativo sobre esses tópicos foi fornecido aos pacientes. } \\
\text { A segunda sessão objetivou mudar crenças equivocadas dos pacientes em relação ao sono, ajudar no controle e promoção do sono. } \\
\text { Na terceira sessão, os pacientes aprenderam as técnicas de PMR e foram incentivados a realizá-las em casa três vezes ao dia. Além } \\
\text { disso, um CD que fornecia um guia para relaxamento em casa foi entregue aos pacientes. }\end{array}$} \\
\hline
\end{tabular}

continua 
Estudo: Ranjbaran et al. (2015)

\section{Controle}

Cuidado usual que incluía treinamento físico e sessões de educação com foco na mudança do estilo de vida e estratégias de enfrentamento dos problemas psicológicos após cirurgia cardíaca. A rotina usual era fornecida aos pacientes de ambos os grupos três vezes por semana, durante oito semanas.

\section{Mensuração dos resultados}

PSQI e questionários com escala do tipo Likert.

\section{Resultados e Conclusões}

O PSQI avaliou a qualidade do sono dos pacientes em sete domínios: qualidade subjetiva, latência, duração, eficiência, distúrbios, disfunção diurna, e uso de medicamento para dormir ao longo do último mês.

A qualidade do sono foi significativamente melhor entre os pacientes do grupo intervenção em comparação aos do grupo controle.

O modelo PRECED-PROCEED demonstra o processo de planejamento, implementação e avaliação de uma estratégia.

Os resultados do estudo sugerem que adicionar uma intervenção baseada no modelo PRECED-PROCEED ao programa de reabilitação cardíaca pode melhorar a qualidade do sono dos pacientes.

Quatro estudos primários foram categorizados como dispositivos, descritos nos Quadros 10, 11, 12 e 13. 
Quadro 10 - Síntese do estudo 4 categorizado como dispositivos

\begin{tabular}{|c|c|}
\hline Estudo: Hu et al. (2015) & Escore de Jadad: 3 \\
\hline \multicolumn{2}{|l|}{ Objetivo } \\
\hline \multicolumn{2}{|c|}{$\begin{array}{l}\text { Avaliar os efeitos do uso de máscara para olhos e tampões de ouvidos combinados com música sobre o sono e níveis de cortisol e } \\
\text { melatonina de pacientes internados na UTI. }\end{array}$} \\
\hline \multicolumn{2}{|l|}{ Participantes } \\
\hline \multicolumn{2}{|c|}{$\begin{array}{l}\text { Pacientes do sexo masculino e feminino submetidos à cirurgia de revascularização do miocárdio, correções valvares e de cardiopatias } \\
\text { congênitas. }\end{array}$} \\
\hline \multicolumn{2}{|c|}{ Número de participantes } \\
\hline \multicolumn{2}{|c|}{ Total de 45 pacientes, sendo 20 no grupo intervenção e 25 no grupo controle. } \\
\hline \multicolumn{2}{|c|}{ Intervenção } \\
\hline \multicolumn{2}{|c|}{$\begin{array}{l}\text { Durante o pós-operatório na UTI, os enfermeiros auxiliavam os pacientes a colocar a máscara para olhos e os tampões de ouvidos } \\
\text { todos os dias a partir das } 21 \mathrm{~h} \text { até a manhã seguinte. Os pacientes do grupo intervenção receberam os dispositivos } 2 \text { a } 3 \text { dias antes da } \\
\text { cirurgia, para conhecerem e se familiarizarem. } \\
\text { A música gravada era fornecida com fone de ouvido para ser ouvida das } 20 \mathrm{~h} \text { às } 21 \mathrm{~h} \text { e das } 7 \text { h } 30 \text { às } 8 \text { h30 todos os dias após a cirurgia, } \\
\text { com duração de } 30 \text { minutos. Os estilos de música eram clássica, sons da natureza e cantos de pássaros. }\end{array}$} \\
\hline \multicolumn{2}{|l|}{ Controle } \\
\hline \multicolumn{2}{|c|}{ Cuidado usual, os colaboradores da unidade foram orientados a não ter atenção especial para reduzir o barulho durante o estudo. } \\
\hline Mensuração dos resultado & \\
\hline
\end{tabular}




\section{Resultados e Conclusões}

A qualidade subjetiva do sono do paciente foi avaliada entre o primeiro e segundo dia após transferência da UTI para a enfermaria usando a RCSQ.

O PSQI foi aplicado entre os pacientes para avaliar a qualidade do sono um mês antes da cirurgia.

Os níveis de melatonina e cortisol foram mensurados por meio da coleta noturna de urina das 20h às 8h um dia antes da cirurgia e no primeiro e segundo dias de pós-operatório.

Os níveis de ruído e luminosidade na UTI foram medidos das $20 \mathrm{~h}$ às $8 \mathrm{~h}$ usando medidor digital de nível de ruído e detector de luz, respectivamente.

Os participantes do grupo intervenção apresentaram qualidade do sono significativamente melhor do que os do grupo controle. Houve resultados significativamente melhores em cinco dos seis itens da escala no grupo intervenção: profundidade do sono, tempo para adormecer, número de despertares após adormecer, eficiência e qualidade percebida do sono.

Não houve diferença significativa nos níveis de cortisol e melatonina entre os pacientes dos dois grupos. Após a cirurgia, evidenciou-se redução e aumento significativos nos níveis de melatonina e cortisol, respectivamente.

Os resultados mostraram que não houve diferença nos níveis de ruído e luminosidade medidos durante a noite nos dois grupos.

A combinação das intervenções não farmacológicas é favorável à promoção do sono de pacientes internados na UTI, pois elas ajudam o paciente a adormecer e manter o sono mediante redução da interferência dos estímulos ambientais e o alívio da ansiedade. Os níveis de melatonina e cortisol podem sofrer influência de diversos fatores, como tempo de cirurgia, uso de medicamentos e diferenças individuais. 
Quadro 11 - Síntese do estudo 8 categorizado como dispositivos

\begin{tabular}{|c|c|}
\hline Estudo: Casida et al. (2013) & Escore de Jadad: 3 \\
\hline \multicolumn{2}{|l|}{ Objetivo } \\
\hline \multicolumn{2}{|c|}{$\begin{array}{l}\text { Avaliar a viabilidade e a aceitação do programa guiado por imagens em promover o sono e reduzir a resposta inflamatória dos } \\
\text { pacientes após cirurgia cardíaca. } \\
\text { Identificar e descrever as diferenças no padrão do sono e níveis de cortisol e marcadores inflamatórios nos pacientes que usaram e nos } \\
\text { que não usaram o programa. }\end{array}$} \\
\hline \multicolumn{2}{|l|}{ Participantes } \\
\hline \multicolumn{2}{|c|}{$\begin{array}{l}\text { Pacientes do sexo masculino e feminino submetidos à cirurgia de revascularização do miocárdio, correções valvares, e } \\
\text { revascularização do miocárdio e correção valvar em um mesmo procedimento. }\end{array}$} \\
\hline \multicolumn{2}{|l|}{ Número de participantes } \\
\hline \multicolumn{2}{|c|}{ Total de 40 pacientes, sendo 20 em cada grupo. } \\
\hline \multicolumn{2}{|l|}{ Intervenção } \\
\hline $\begin{array}{l}\text { Programa de imagem guiada co } \\
\text { meditação usadas para direcior } \\
\text { alcançar um estado tranquilo e } \\
\text { primeiro ao quarto dia de pós-or }\end{array}$ & $\begin{array}{l}\text { de MP3 e fones de ouvido. O programa consiste em um conjunto de técnicas de relaxamento e } \\
\text { enção do paciente para longe de estímulos desagradáveis (exemplo: dor) com a finalidade de } \\
\text { com progressão para o sono natural. A intervenção era aplicada ao paciente entre } 22 \mathrm{~h} \text { e } 24 \mathrm{~h} \text { do } \\
\text { o, com as luzes apagadas e porta fechada, com duração de pelo menos } 1 \mathrm{~h} \text { por noite. Toda vez }\end{array}$ \\
\hline
\end{tabular}

continua 
que o sono do paciente fosse interrompido durante a noite, ele tinha a opção de ouvir o programa novamente. O pacote era mantido na cabeceira da cama do paciente para facilitar o uso.

\section{Controle}

Cuidado usual.

\section{Mensuração dos resultados}

Actigrafia, Visual Analog Sleep Scales (VASS) e níveis de cortisol e de proteína C-reativa.

\section{Resultados e Conclusões}

A viabilidade da intervenção foi avaliada com a proporção do número de pacientes que completaram o estudo e o número de pacientes que abandonaram a pesquisa.

A aceitabilidade da intervenção foi medida por um instrumento com escala do tipo Likert desenvolvido pelo pesquisador.

A aceitação e a viabilidade do programa de imagem guiada foram avaliadas no quinto dia de pós-operatório, após término da intervenção de quatro dias.

A taxa de conformidade dos pacientes com o uso do programa no estudo foi de $85 \%$ no primeiro dia para $100 \%$ do segundo ao quarto dia; a média da frequência de uso do programa foi de 1,68 vez por noite. Em geral, os pacientes relataram alta conformidade com os itens relacionados aos benefícios e satisfação do programa como intervenção para promoção do sono. 
O padrão do sono do paciente foi operacionalizado pela latência e pelo tempo total do sono, medidos por meio da actigrafia das $22 \mathrm{~h}$ às $8 \mathrm{~h}$ nos quatro dias do estudo.

A percepção do paciente sobre a qualidade do sono foi medida por três itens da VASS (duração do sono, número de despertares após início do sono e sono restaurador) nas manhãs do primeiro ao quarto dia de pós-operatório.

O cortisol na saliva e a proteína C-reativa (PCR) no sangue foram selecionados para a mensuração da resposta inflamatória. As coletas ocorreram entre $6 \mathrm{~h}$ e $8 \mathrm{~h}$ durante o período do estudo.

Os pacientes do grupo intervenção apresentaram melhora estável da qualidade e latência do sono ao longo do período do estudo. Houve menor latência e maior escore de qualidade do sono nesses pacientes em comparação aos do grupo controle. Porém, os pacientes do grupo controle apresentaram maior tempo de duração total do sono.

Também não houve diferença significativa nos níveis de cortisol e PCR entre os participantes dos grupos do estudo. No entanto, observou-se considerável declínio nesses níveis entre os pacientes do grupo intervenção.

Houve diferenças de resultados com medidas objetivas e subjetivas do sono entre os pacientes desse estudo. Os resultados do estudo sugerem que o programa pode facilitar o início do sono e aumentar a percepção de qualidade do sono em virtude de efeitos como redução da ansiedade e da dor. Entretanto, fatores ambientais como ruído, cuidados e luminosidade colaboram com os despertares do paciente, o que impossibilita uma longa duração do sono.

O uso do programa isoladamente pode não ser suficiente para sustentar a continuidade do sono e reduzir a resposta inflamatória dos pacientes em recuperação de cirurgia cardíaca. A intervenção pode obter sucesso, porém, se for integrada com outras terapias para manejo do sono de pacientes em recuperação cirúrgica. 
Quadro 12 - Síntese do estudo 9 categorizado como dispositivos

\begin{tabular}{|c|c|}
\hline Estudo: Zimmerman et al. (1996) ${ }^{93}$ & Escore de Jadad: 1 \\
\hline \multicolumn{2}{|l|}{ Objetivo } \\
\hline \multicolumn{2}{|c|}{$\begin{array}{l}\text { Determinar os efeitos de intervenções de enfermagem não invasivas, como música, vídeo de música e repouso sobre os escores de dor } \\
\text { e qualidade do sono de pacientes submetidos à cirurgia de revascularização do miocárdio. }\end{array}$} \\
\hline \multicolumn{2}{|l|}{ Participantes } \\
\hline \multicolumn{2}{|c|}{ Pacientes do sexo masculino e feminino submetidos à cirurgia de revascularização do miocárdio. } \\
\hline \multicolumn{2}{|l|}{ Número de participantes } \\
\hline \multicolumn{2}{|c|}{ Total de 96 pacientes, sendo 64 divididos igualmente em dois grupos intervenção diferentes e 32 no grupo controle. } \\
\hline \multicolumn{2}{|c|}{ Intervenção } \\
\hline \multicolumn{2}{|c|}{$\begin{array}{l}\text { Grupo intervenção música: os participantes tinham a opção de escolher uma música entre cinco tipos diferentes, todas com estilo } \\
\text { tranquilizador, para facilitar o relaxamento. A música era fornecida por fone de ouvido. } \\
\text { Grupo intervenção vídeo com música: os participantes recebiam três opções de fita de videocassete que combinavam música } \\
\text { instrumental suave e imagens de diferentes cenas. }\end{array}$} \\
\hline \multicolumn{2}{|l|}{ Controle } \\
\hline \multicolumn{2}{|c|}{ Repouso programado por um período de 30 minutos, durante o qual o paciente não podia ser perturbado. } \\
\hline Mensuração dos resultados & \\
\hline
\end{tabular}




\section{Estudo: Zimmerman et al. (1996) ${ }^{93}$ Escore de Jadad: 1}

afetivo, sensorial e intensidade da dor; e RCSQ.

\section{Resultados e Conclusões}

As intervenções nos três grupos foram realizadas em duas sessões, no primeiro e segundo dias de pós-operatório da cirurgia cardíaca, com duração de 30 minutos. Os participantes eram transferidos da UTI antes de iniciar a sessão e, sempre que possível, a intervenção foi aplicada no mesmo horário em ambos os dias para controle das variações circadianas. As sessões aconteceram no período da tarde ou começo da noite. Houve o cuidado para diminuir as atividades com os pacientes durante as sessões e garantir que estivessem confortáveis em uma cama ou poltrona.

Foi utilizado a RCSQ para mensurar a qualidade do sono dos pacientes antes e após a cirurgia. Não houve diferença significativa nos escores de sono pré-cirurgia entre os pacientes dos três grupos.

Os dados foram coletados na manhã do terceiro dia de pós-operatório, mostrando que os participantes do grupo vídeo com música apresentaram significativamente sono de melhor qualidade em comparação aos do grupo repouso.

Os pacientes do grupo música também apresentaram melhores escores de sono em comparação aos do grupo repouso, porém não de forma significativa.

A dor foi avaliada pela VRS antes e depois de cada sessão nos pacientes dos três grupos e mostrou que houve diminuição na intensidade da dor ao longo do tempo em todos os pacientes, sem diferença entre os grupos. Os dados coletados do MPQ mostraram melhora da dor do segundo ao terceiro dia em todos os pacientes. Os participantes do grupo música apresentaram significativamente menores escores de dor em comparação aos do grupo controle. 


\section{Estudo: Zimmerman et al. (1996) ${ }^{93}$ Escore de Jadad: 1}

Os resultados do estudo sugerem que as três intervenções (música, vídeo com música e repouso) ajudam a reduzir os escores de dor, sendo então comparáveis para o uso na prática clínica. Entretanto, indicam que a música apresenta mais vantagens em reduzir o componente sensorial da dor no período de pós-operatório imediato. Os enfermeiros devem incentivar a música por períodos programados, especialmente à noite, em virtude do potencial da intervenção em reduzir a dor e melhorar o sono do paciente. Além disso, ficou claro que períodos de repouso sem interrupções aos pacientes são essenciais para a recuperação física e emocional. 
Quadro 13 - Síntese do estudo 10 categorizado como dispositivos

\begin{tabular}{|c|c|}
\hline Estudo: Williamson (1992) & Escore de Jadad: 3 \\
\hline \multicolumn{2}{|l|}{ Objetivo } \\
\hline \multicolumn{2}{|c|}{$\begin{array}{l}\text { Determinar a utilidade de fita gravada com sons do oceano (ruído branco) em melhorar o padrão do sono de pacientes submetidos à } \\
\text { cirurgia de revascularização do miocárdio. } \\
\text { Investigar a influência do ruído branco sobre o padrão do sono noturno de pacientes após a transferência da UTI. }\end{array}$} \\
\hline \multicolumn{2}{|l|}{ Participantes } \\
\hline \multicolumn{2}{|c|}{ Pacientes do sexo masculino e feminino submetidos à cirurgia de revascularização do miocárdio. } \\
\hline \multicolumn{2}{|c|}{ Número de participantes } \\
\hline \multicolumn{2}{|c|}{ Total de 60 pacientes, sendo 30 pacientes em cada grupo. } \\
\hline \multicolumn{2}{|c|}{ Intervenção } \\
\hline \multicolumn{2}{|c|}{$\begin{array}{l}\text { Fitas gravadas com ruído branco, ou seja, sons de chuva, ondas do mar e quedas de água. O grupo intervenção tinha a opção de } \\
\text { escolher um dos sons. O som era iniciado entre } 20 \mathrm{~h} 30 \text { e } 21 \mathrm{~h} \text { e tocava durante toda a noite, após a transferência da UTI para a unidade } \\
\text { de terapia semi-intensiva, por três noites consecutivas. A fita gravada era colocada em uma mesa ao lado da cama do paciente. }\end{array}$} \\
\hline \multicolumn{2}{|l|}{ Controle } \\
\hline \multicolumn{2}{|c|}{ Nenhum controle do ambiente, som usual. } \\
\hline \multicolumn{2}{|l|}{ Mensuração dos resultados } \\
\hline SSQ. & \\
\hline
\end{tabular}




\section{Estudo: Williamson (1992) ${ }^{94}$}

\section{Resultados e Conclusões}

O sono pode ser alterado por fatores fisiológicos, psicológicos e ambientais. A pessoa pode se ajustar ao ambiente por acomodação ou por assimilação. A acomodação ocorre quando a pessoa modifica o comportamento para se adaptar ao ambiente, ao passo que a assimilação ocorre quando a pessoa altera o ambiente para encontrar as necessidades pessoais. O ruído branco pode ajudar a pessoa a assimilar os sons do ambiente e auxiliar no sono.

O padrão do sono dos participantes do estudo foi avaliado no dia da internação hospitalar, um dia antes da cirurgia, para mensurar o sono usual do paciente em casa. Após a cirurgia, os dados foram coletados na manhã da quarta noite após a transferência do paciente da UTI.

A escala de RCSQ aplicada aos pacientes avaliou seis variáveis do sono: latência, profundidade, qualidade, escore total, número de despertares e retorno ao sono. Houve melhora significativa em cinco variáveis da escala; apenas a latência do sono foi pior após a intervenção.

Os pacientes que receberam o ruído branco relataram retorno ao sono após um despertar similar aos hábitos antes da cirurgia.

Os escores de sono de ambos os grupos foram muito similares antes da cirurgia. O grupo intervenção relatou melhor qualidade do sono após a cirurgia em comparação ao sono prévio.

Os resultados do estudo mostram que os sons classificados como ruído branco podem influenciar positivamente o padrão do sono noturno de pacientes internados após cirurgia cardíaca. O ruído branco pode colaborar para o paciente não focar em situações estressantes. Outra vantagem dessa intervenção é o controle que o paciente exerce sobre seu próprio cuidado, pois o uso indiscriminado do som pode causar desconforto. 
Entre os estudos primários da RS, três se enquadraram na categoria estratégia educacional, como mostram os Quadros 14, 15 e 16 .

Quadro 14 - Síntese do estudo 1 categorizado como estratégia educacional

\begin{tabular}{|c|c|}
\hline Estudo: Zimmerman et al. (2007) ${ }^{95}$ & Escore de Jadad: 2 \\
\hline \multicolumn{2}{|l|}{ Objetivo } \\
\hline \multicolumn{2}{|c|}{$\begin{array}{l}\text { Examinar o efeito de uma intervenção de gerenciamento de sintomas na evolução de sintomas no período pós-operatório, na função } \\
\text { física e na atividade física de mulheres submetidas à cirurgia de revascularização do miocárdio. } \\
\text { Determinar se houve diferença nos escores dos sintomas (frequência e severidade) entre as mulheres que receberam a intervenção. }\end{array}$} \\
\hline \multicolumn{2}{|c|}{ Participantes } \\
\hline \multicolumn{2}{|c|}{ Pacientes do sexo feminino submetidas à cirurgia de revascularização do miocárdio. } \\
\hline \multicolumn{2}{|l|}{ Número de participantes } \\
\hline \multicolumn{2}{|c|}{ Total de 40 pacientes, divididos em 23 no grupo intervenção e 17 no grupo controle. } \\
\hline \multicolumn{2}{|c|}{ Intervenção } \\
\hline $\begin{array}{l}\text { A intervenção foi construída com bas } \\
\text { miocárdio para manejo de sintomas } \\
\text { autoeficácia e expectativas. A interv } \\
\text { chamado }\end{array}$ & $\begin{array}{l}\text { nos principais assuntos que o paciente necessita saber após cirurgia de revascularização do } \\
\text { promoção do funcionamento físico e da atividade física, como conhecimento, habilidades, } \\
\text { nça foi entregue aos pacientes através de um dispositivo eletrônico conectado ao telefone }\end{array}$ \\
\hline
\end{tabular}

continua 


\section{\begin{tabular}{l|l} 
Estudo: Zimmerman et al. (2007) & Escore de Jadad: 2
\end{tabular}}

Health Buddy, que continha roteiros algorítmicos para avaliar o sintoma e fornecer estratégias para auxiliar no seu manejo. As sessões foram realizadas diariamente por seis semanas.

\section{Controle}

Cuidado usual.

\section{Mensuração dos resultados}

Cardiac Symptom Survey, que avalia a frequência e severidade de 10 sintomas comuns no pós-operatório de revascularização do miocárdio, um dos quais é a dificuldade para dormir.

\section{Resultados e Conclusões}

Os participantes do estudo foram avaliados em dois momentos: seis semanas e três meses após a cirurgia, por meio de entrevista telefônica. O grupo intervenção apresentou significativamente menor escore de fadiga após seis semanas da cirurgia e maior nível de atividade física após três meses de pós-operatório. Em seis semanas e três meses após a cirurgia, constatou-se correlação significativa entre os sintomas avaliados e o funcionamento físico. O sintoma problemas para dormir em seis semanas após a cirurgia foi menos frequente entre os pacientes do grupo intervenção, porém a diferença não foi significativa. Os resultados sugerem que os sintomas como depressão, dor, fadiga e problemas para dormir são prevalentes e persistentes entre mulheres após a cirurgia de revascularização do miocárdio, sendo necessárias intervenções biocomportamentais para manejo desses sintomas e para auxiliar na recuperação física e emocional. 
Quadro 15 - Síntese do estudo 2 categorizado como estratégia educacional

\begin{tabular}{|c|c|}
\hline Estudo: Guo, East e Arthur (2012) & Escore de Jadad: 3 \\
\hline \multicolumn{2}{|l|}{ Objetivo } \\
\hline \multicolumn{2}{|c|}{$\begin{array}{l}\text { Determinar se a intervenção educacional no período pré-operatório reduz ansiedade, depressão e dor e melhora a recuperação pós- } \\
\text { operatória entre pacientes submetidos à cirurgia cardíaca. }\end{array}$} \\
\hline \multicolumn{2}{|l|}{ Participantes } \\
\hline \multicolumn{2}{|c|}{$\begin{array}{l}\text { Pacientes do sexo masculino e feminino submetidos à cirurgia de revascularização do miocárdio, correções valvares, cirurgias da aorta, } \\
\text { e revascularização do miocárdio e correção valvar em um mesmo procedimento. }\end{array}$} \\
\hline \multicolumn{2}{|l|}{ Número de participantes } \\
\hline \multicolumn{2}{|c|}{ Total de 135 pacientes, sendo 68 no grupo intervenção e 67 no grupo controle. } \\
\hline \multicolumn{2}{|l|}{ Intervenção } \\
\hline \multicolumn{2}{|c|}{$\begin{array}{l}\text { Educação pré-operatória realizada dois a três dias antes da cirurgia por meio de orientação verbal de } 15 \text { a } 20 \text { minutos + folheto } \\
\text { informativo "Your heart surgery" + visita de enfermeira especialista. A versão final do folheto foi avaliada por especialistas na área e } \\
\text { pacientes submetidos à cirurgia cardíaca. O conteúdo do folheto era dividido em sessões: preparo pré-operatório, internação na UTI } \\
\text { após a cirurgia, retorno à enfermaria e recuperação no domicílio. Também era fornecido um contato telefônico para casos de ajuda } \\
\text { após a alta hospitalar. }\end{array}$} \\
\hline Controle & \\
\hline
\end{tabular}




\section{Estudo: Guo, East e Arthur (2012) ${ }^{96}$ Escore de Jadad: 3}

\section{Mensuração dos resultados}

Hospital Anxiety and Depression Scale (HADS) para avaliar ansiedade e depressão.

Brief Pain Inventory-short form (BPI-sf) para mensurar a intensidade da dor e a sua interferência nas atividades diárias, entre elas, dormir. A intensidade da dor era avaliada em quatro domínios: pior, mínima, média, agora. A interferência da dor na atividade diária era mensurada por escala analógica visual de zero a dez.

\section{Resultados e Conclusões}

Os dados dos pacientes foram coletados sete dias após a cirurgia. Os participantes do grupo intervenção apresentaram significativamente menores escores de depressão e ansiedade e menos interferência da dor sobre a capacidade de dormir em comparação aos do grupo controle. Os participantes do grupo controle relataram problemas mais frequentes para dormir. Os resultados do estudo sugerem que essa forma de educação pré-operatória é efetiva na recuperação psicológica entre pacientes submetidos à cirurgia cardíaca. Essa prática deve ser incorporada à rotina dos hospitais por existir evidência dos benefícios. 
Quadro 16 - Síntese do estudo 5 categorizado como estratégia educacional

\begin{tabular}{|c|c|}
\hline Estudo: Johansson et al. (2014) ${ }^{97}$ & Escore de Jadad: 2 \\
\hline \multicolumn{2}{|l|}{ Objetivo } \\
\hline \multicolumn{2}{|c|}{$\begin{array}{l}\text { Avaliar a eficácia de um programa individualizado em promover a capacidade de gerir o autocuidado, a fim de melhorar a atividade do } \\
\text { sono em pacientes submetidos ao tratamento de doença arterial coronariana (DAC). }\end{array}$} \\
\hline \multicolumn{2}{|l|}{ Participantes } \\
\hline \multicolumn{2}{|c|}{$\begin{array}{l}\text { Pacientes do sexo masculino e feminino submetidos à cirurgia de revascularização do miocárdio, intervenção coronariana percutânea e } \\
\text { tratamento clínico. }\end{array}$} \\
\hline \multicolumn{2}{|l|}{ Número de participantes } \\
\hline \multicolumn{2}{|c|}{$\begin{array}{l}\text { Total de } 47 \text { pacientes com DAC, sendo } 24 \text { no grupo intervenção e } 23 \text { no grupo controle. Submetidos à cirurgia cardíaca: total de nove } \\
\text { pacientes, sendo cinco no grupo intervenção e quatro no controle. }\end{array}$} \\
\hline \multicolumn{2}{|l|}{ Intervenção } \\
\hline \multicolumn{2}{|c|}{$\begin{array}{l}\text { Programa de educação individualizado para promover o autocuidado do paciente em atividades do sono. Os hábitos de sono e estilo de } \\
\text { vida formaram a base para a criação de metas individuais em conjunto com a enfermeira. } \\
\text { O fisioterapeuta realizou aconselhamento individual no treinamento físico e exercícios de relaxamento, além de fornecer CD com } \\
\text { programa de relaxamento. Foi entregue ao paciente um folheto informativo sobre o sono e estresse. }\end{array}$} \\
\hline Controle & \\
\hline
\end{tabular}


Estudo: Johansson et al. (2014) $)^{97}$

\section{Escore de Jadad: 2}

Mensuração dos resultados

Uppsala Sleep Inventory (USI), Diário do sono, Actigrafia e ESS.

\section{Resultados e Conclusões}

A coleta de dados foi realizada por meio de questionários, diário do sono e actigrafia por 10 dias consecutivos, com um follow-up após três a quatro meses.

Os participantes do grupo intervenção apresentaram resultados positivos após o programa educativo. Os pacientes relataram no diário do sono melhor qualidade, eficiência e duração do sono após a intervenção. A actigrafia mostrou melhor eficiência do sono nos pacientes do grupo intervenção.

Houve melhora estatisticamente significativa na qualidade e eficiência do sono e no número de despertares noturnos mensurados pelo USI nos pacientes do grupo intervenção em comparação aos do grupo controle. Queixas relacionadas ao sono não restaurador também foram menores entre os pacientes do grupo intervenção. Os resultados do estudo sugerem que o programa individualizado para promover o autocuidado do paciente em atividades do sono, incluindo intervenções de relaxamento, pode melhorar a qualidade do sono. O programa individualizado pode ser facilmente aplicado, portanto, deve ser incentivado na prática clínica diária. 
Três ensaios clínicos utilizaram técnicas de relaxamento para promoção do sono de pacientes submetidos à cirurgia cardíaca. Nerbass et al. ${ }^{89}$ adotaram a massagem como intervenção, porém não alcançaram resultados significativos sobre a qualidade do sono.

O estudo de Akinci et al. ${ }^{90}$ testou a efetividade do treinamento de postura e relaxamento e mostrou melhoria significativa $(p=0.026)$ no escore total do sono pelo PSQI dos pacientes do grupo intervenção em comparação aos do grupo controle.

Ranjbaran et al. ${ }^{91}$ também utilizaram medidas de relaxamento muscular progressivo como estratégia para promoção do sono dos pacientes e alcançaram diferença significativa $(p<0.001)$ na qualidade do sono dos grupos estudados. Esse três estudos ${ }^{89-91}$ utilizaram mais de uma técnica para a mensuração do sono, sendo a PSQI utilizada nos três.

Em relação à qualidade metodológica dos ensaios clínicos da $\mathrm{RS}$ incluídos na categoria técnicas de relaxamento, um estudo ${ }^{90}$ foi classificado como moderada qualidade e dois estudos ${ }^{89,91}$, como baixa qualidade. Entre esses estudos, os que mostraram resultados estatisticamente significativos foram classificados como baixa $^{91}$ e moderada qualidade ${ }^{90}$.

Alguns autores testaram intervenções para melhorar a qualidade do sono dos pacientes após cirurgia cardíaca por meio do relaxamento, porém utilizando equipamentos como fone de ouvido ${ }^{66,93}$, programa de MP3 com fone de ouvido ${ }^{92}$ e fita com produção sonora ${ }^{94}$. Pelo fato de a característica mais marcante nesses três ensaios clínicos ser o uso dos equipamentos, estes foram categorizados como intervenções com dispositivos.

Dentre os estudos ${ }^{66,92-94}$ que utilizaram equipamentos para promover 0 relaxamento e melhorar a qualidade do sono dos pacientes, três ${ }^{66,92,94}$ evidenciaram melhora significativa da qualidade do sono nos participantes do grupo intervenção em comparação aos do grupo controle.

Hu et al. ${ }^{66}$ alcançaram qualidade subjetiva do sono significativamente maior e menor percepção de barulho noturno (ambos $p$ < 0.05) por meio da intervenção que combinou dispositivos de proteção aos estímulos ambientais e fone de ouvido com música. Essa estratégia para promoção do sono de pacientes em período pós- 
operatório de cirurgia cardíaca atingiu diferentes efeitos: tanto induziu ao relaxamento e diminuiu a ansiedade, como minimizou as interrupções do sono por fatores externos.

Os estudos de Zimmerman et al. ${ }^{93}$ e Williamson ${ }^{94}$ utilizaram a música como estratégia para promoção do sono dos pacientes. O primeiro estudo ${ }^{93}$ mostrou que os pacientes do grupo vídeo com música apresentaram melhores escores de sono ( $p$ $<0.05)$ que os do grupo repouso. Já no segundo estudo ${ }^{94}$, houve melhora em cinco variáveis do sono entre os pacientes que ouviram a música: maior profundidade do sono $(p=0.001)$, menor número de despertares durante a noite $(p=0.026)$, retorno ao sono mais rapidamente $(p=0.009)$, qualidade do sono $(p=0.003)$ e escore total do sono $(p=0.002)$.

O estudo de Casida et al. ${ }^{92}$ apresentou menor latência do sono nos pacientes após a intervenção denominada programa de imagem guiada, porém a diferença não foi significativa entre os grupos.

Notou-se que a mesma técnica de mensuração do sono, a RCSQ, foi adotada entre os estudos que apresentaram resultados significativos sobre a qualidade do sono dos pacientes por meio de intervenções com o uso de equipamentos.

Em relação ao escore de Jadad dos estudos que testaram intervenções com dispositivos para promoção do sono dos pacientes, as classificações foram moderada (estudo 4, 8 e 10) ${ }^{66,92,94}$ e baixa qualidade (estudo 9$)^{93}$. Entre os estudos com significância estatística, houve estudo que se enquadrou em baixa qualidade (estudo 9$)^{92}$ e em moderada qualidade pelo escore de Jadad (estudo 10) ${ }^{95}$.

Três ensaios clínicos ${ }^{95-97}$ testaram estratégias educacionais para promoção do sono de pacientes submetidos à cirurgia cardíaca. Guo, East e Arthur ${ }^{96}$ orientaram os pacientes no período pré-operatório sobre detalhes da cirurgia cardíaca, internação hospitalar, recuperação e reabilitação, a fim de reduzir a ansiedade e melhorar a recuperação, sendo o sono um dos domínios avaliados. O estudo apresentou resultado significativo $(\mathrm{p}=0.02)$, pacientes com melhor domínio sobre a dor no pós-operatório e consequentemente menor interferência sobre o sono e menos problemas para dormir. 
Zimmerman et al. ${ }^{95}$ utilizaram orientações construídas com base nos principais assuntos que os pacientes em pós-operatório de cirurgia cardíaca precisam conhecer: conhecimento, habilidades, expectativas e autoeficácia necessários para o manejo de seus sintomas e promoção do funcionamento físico e da atividade física. Entretanto, não houve diferença entre os participantes do estudo com relação às variáveis analisadas.

O estudo realizado por Johansson et al. ${ }^{97}$ utilizou as três diferentes estratégias para promover o sono de pacientes submetidos à cirurgia de revascularização do miocárdio, sendo programa de educação individualizado, CD com programa de relaxamento, treinamento físico e folheto informativo. Este estudo mostrou melhora significativa da qualidade do sono entre os participantes do grupo intervenção.

Os três estudos categorizados como estratégias educacionais apresentaram escore de Jadad diferentes ${ }^{95-97}$. Os estudos de Guo, East e Arthur ${ }^{96}$ e Johansson et al. ${ }^{97}$ obtiveram resultados significativamente melhores sobre o sono dos pacientes do grupo intervenção em comparação aos do grupo controle e foram classificados como moderada e baixa qualidade, respectivamente. O estudo de Zimmerman et al. ${ }^{95}$ que não obteve diferença significativa entre os participantes dos grupos, enquadrou-se como de baixa qualidade.

Entre os estudos com resultados satisfatórios e estatisticamente significativos, as intervenções não farmacológicas para o tratamento da alteração do padrão do sono categorizadas nesta RS como dispositivos foram as mais frequentes. No entanto, além do uso de equipamentos, característica marcante dos estudos, essas intervenções promovem o sono por meio de relaxamento, por exemplo, com música.

\subsection{SÍNTESE DOS ESTUDOS PRIMÁRIOS SEGUNDO DELINEAMENTO DE ESTUDO}

Todos os estudos comparam a intervenção testada com o controle, o qual é descrito como cuidado usual. Apenas dois artigos ${ }^{92,95}$ não descrevem o cuidado usual utilizado no estudo, como mostram os quadros acima. 
O período de aplicação da intervenção nos ensaios clínicos analisados foi uma variável que demonstrou resultados distintos: $60 \%$ dos estudos realizaram intervenções pontuais no pós-operatório imediato (estudos 3, 4, 8, 9 e 10) ${ }^{66,89,92-94}$ e no pré-operatório imediato (estudo 2 ) $^{96}$. Os outros estudos variaram de duas semanas (estudo 6) ${ }^{90}$ a quatro meses (estudo 5$)^{97}$.

A maioria dos estudos primários testou a efetividade de intervenção não farmacológica para o tratamento da alteração do padrão do sono em pacientes hospitalizados na UTI (estudo 4) ${ }^{66}$, unidade de terapia semi-intensiva (estudo 10) ${ }^{94}$ ou enfermaria (estudos 2, 3, 8 e 9) 89,92,93,96 em período pós-operatório imediato, até uma semana após a cirurgia. Quatro estudos (estudos 1, 5, 6 e 7) 90,91,95,97 mensuraram o sono de pacientes submetidos à cirurgia cardíaca após a alta hospitalar em período pós-operatório tardio, que foi de duas semanas a quatro meses, cujos resultados foram avaliados em clínicas de reabilitação ou ambulatório.

As técnicas subjetivas predominaram como método adotado para a mensuração do sono dos pacientes estudados. Apenas Casida et al. ${ }^{92} \mathrm{e}$ Johansson ${ }^{97}$ usaram o método objetivo da actigrafia. Muitos autores utilizaram mais de um instrumento para mensurar o sono dos pacientes, sendo o PSQI o mais frequente.

O total de participantes dos estudos primários da atual RS foi de 641 pacientes. O tamanho da amostra final dos ensaios clínicos variou bastante; o estudo com menor número de participantes foi o de Akinci et al. ${ }^{90}$, com 24 pacientes, e com maior número foi o de Guo, East e Arthur ${ }^{96}$, com 135 pacientes.

Entre os pacientes estudados nos artigos da atual RS estão os submetidos à cirurgia de revascularização do miocárdio, às correções valvares e de cardiopatia congênita, cirurgias da aorta e cirurgia combinada (coronária e valva em um mesmo procedimento). No entanto, pacientes em pós-operatório de RM foram os mais comumente encontrados nos estudos. Pacientes submetidos à cirurgia de RM compuseram todas as amostras dos artigos, de modo único ou como parte.

A idade média dos participantes dos estudos primários foi de 61,4 anos. $O$ gênero predominante em todos os ensaios clínicos foi o masculino, com frequência relativa entre $54,9 \%$ (estudo 2$)^{96}$ e $87,5 \%$ (estudo 6$)^{90}$. Apenas um artigo (estudo 
1) ${ }^{95}$ foi composto por $100 \%$ de mulheres, pois esse era um critério de inclusão do estudo.

Com relação aos autores dos estudos primários incluídos na revisão sistemática, $50 \%$ foram enfermeiros, $40 \%$ fisioterapeutas e um estudo não mencionou. 
Todos os estudos incluídos na atual RS mostraram que intervenções não farmacológicas apresentam resultados positivos sobre o sono dos pacientes, porém nem todos significativos. Alguns estudos apresentaram redução na latência e/ou na interrupção e outros mostraram melhora da percepção do paciente sobre a qualidade do sono. Diversas intervenções não farmacológicas estão sendo testadas para o tratamento da alteração do padrão do sono, tais como massagem, sonoridade musical ou da natureza, tampões de ouvidos e máscara para olhos, treinamento de relaxamento muscular e estratégias educacionais.

Para reafirmar a utilização das intervenções não farmacológicas, Tamrat, Huynh-Le e Goyal ${ }^{68}$ conduziram uma revisão com o objetivo de identificar estudos primários que testaram intervenções não farmacológicas para a promoção do sono de pacientes internados em unidades de diferentes especialidades (cardiologia, oncologia, psiquiatria e clínica-cirúrgica), exceto em terapia intensiva. Nos resultados foram incluídos 13 estudos com intervenções agrupadas em três categorias gerais: técnicas de relaxamento; minimização da interrupção do sono com a criação de um momento de silêncio noturno; exposição à terapia de luz artificial durante o dia para melhora do sono noturno. Os resultados mostraram heterogeneidade entre os estudos com relação a população, tipo de intervenção, método de mensuração do padrão do sono e tempo de seguimento. Além disso, houve escassez de estudos randomizados, fatores estes que dificultam a criação de um protocolo de cuidados para a melhoria da qualidade do sono de pacientes internados que possam ser inseridos na rotina da prática hospitalar.

Hellström, Fagerström e Willman ${ }^{98}$ desenvolveram uma RS cujo objetivo foi identificar estudos primários que avaliaram a eficácia das intervenções de enfermagem em promover o sono de pacientes gerais internados. Nos resultados foram incluídos nove estudos que testaram intervenções como massagem, relaxamento, aromaterapia, acupuntura, higiene do sono e música. Os resultados mostraram que intervenções como massagem, acupuntura e música foram efetivas na melhoria da qualidade do sono de pacientes. No entanto, os estudos foram considerados de baixa evidência e houve inconsistência entre os métodos utilizados para mensuração do sono. Esses fatores levaram os autores a concluírem sobre a 
necessidade de pesquisas futuras para se assegurar quanto ao melhor método de intervenção para melhoria do sono entre pacientes internados.

Reiterando os resultados encontrados por Tamrat ${ }^{68}$ e Hellström ${ }^{98}$, na pesquisa atual, as técnicas de indução ao relaxamento e as que controlam os fatores ambientais foram as mais utilizadas nos ensaios clínicos selecionados. As características dos ensaios clínicos da atual revisão também encontraram heterogeneidade no que concerne ao tamanho da amostra, ao tipo de intervenção utilizada, à técnica para mensuração do padrão do sono, ao tempo de seguimento para avaliação dos sujeitos e ao local do estudo.

Os resultados da presente $\mathrm{RS}$ mostram predomínio das intervenções não farmacológicas categorizadas como dispositivos (estudos 4, 8, 9 e 10). Entre os estudos que se enquadraram nessa categoria, três apresentaram moderada qualidade metodológica pelo escore de Jadad. Visto que nenhum estudo incluído na revisão foi classificado em alta qualidade metodológica, considerou-se importante salientar os benefícios encontrados na melhoria do padrão do sono em tais pesquisas e o incentivo para a adoção de semelhantes práticas.

O estudo de $\mathrm{Hu}$ et al. ${ }^{66}$ refere que intervenções com o uso de dispositivos de proteção ao ruído e à luminosidade são eficazes na promoção do sono dos pacientes pela redução dos estímulos ambientais e sua interferência para melhoria do padrão do sono.

Estudos com diferentes sujeitos mostraram resultados similares. Le Guen et al. ${ }^{67}$ utilizaram protetor auricular e máscara de olhos para analisar pacientes em pósoperatório de cirurgia geral; Richardson et al. ${ }^{99}$ investigaram os mesmos dispositivos em pacientes cardíacos clínicos; e $\mathrm{Hu}$ et al. ${ }^{65}$ compararam duas amostras de sujeitos saudáveis em um ambiente simulado de UTI. Os indivíduos foram expostos ao ruído e à luminosidade, com e sem máscara de olhos e tampões de ouvidos. Os resultados das intervenções nesses três estudos foram significativamente satisfatórios com relação à qualidade subjetiva do sono: Le Guen et al. ${ }^{67}$ demonstraram prevenir a redução no escore basal de qualidade do sono e a diminuição da necessidade de cochilos durante o dia; Richardson et al. ${ }^{99}$ revelaram melhor percepção da qualidade do sono pelo paciente; e Hu et al. ${ }^{65}$ constataram adequada manutenção do sono e menor tempo gasto para adormecer. 
Nesta mesma análise, Neyse et al. ${ }^{100}$ revelaram que a utilização somente de tampões de ouvidos é suficiente para a melhoria da qualidade do sono entre pacientes cardiopatas e ressaltaram a importância do método pelo baixo custo e por ser isento de complicações.

Entre os dispositivos descritos, além da máscara para olhos e tampões de ouvidos, a utilização de dispositivos sonoros parece ser uma importante alternativa para indução do relaxamento. Zimmerman et al. ${ }^{93}$ afirmaram que a utilização da música como estratégia terapêutica para pacientes internados em período pósoperatório melhora os escores de avaliação do padrão do sono.

Dois ensaios clínicos incluídos na atual RS mostraram a efetividade da música na promoção do sono. O estudo de Williamson ${ }^{94}$ testou a influência do white noise em pacientes submetidos à cirurgia cardíaca. $\mathrm{O}$ white noise ou ruído branco é uma gravação com sons da natureza (chuva, ondas e quedas de água) que pode alterar o foco de atenção do paciente e mascarar o ruído do ambiente. Esse estudo revelou que a intervenção com o dispositivo sonoro pode contribuir para o paciente se distanciar dos estímulos ambientais e focar no som relaxante do dispositivo; sendo assim, auxilia no início e na manutenção do sono.

Há evidências de que a experiência sonora está sendo testada em diferentes populações e apresenta efeitos benéficos sobre a qualidade do sono. O estudo de Stanchina et al. ${ }^{101}$ também demonstrou os efeitos benéficos do white noise em reduzir o número de despertares durante o sono em indivíduos saudáveis expostos a um ambiente simulado com ruídos de uma UTI.

Acredita-se que a utilização do white noise entre os pacientes reduza a diferença entre o nível de ruído basal e um pico de ruído, diminua a resposta reflexa do indivíduo diante de um estímulo intenso, proporcione um efeito de propagação sonoro em sua transmissão aos centros de excitação central, mascare os ruídos ambientais e limite a capacidade do indivíduo para discriminar sons facilmente detectáveis $^{101}$.

Su et al. ${ }^{102}$, ao realizarem um ensaio clínico com o objetivo de avaliar os efeitos da música sobre a qualidade objetiva e subjetiva do sono em pacientes internados, concluíram que a música desencadeia uma resposta significativa do sistema nervoso autonômico, com considerável redução da pressão arterial e 
frequência cardíaca entre eles. Além disso, os autores afirmam que ouvir som de piano por pelo menos 30 minutos no período noturno, antes de dormir, induz ao relaxamento, favorece à normalidade do sono e melhora a percepção do paciente sobre a qualidade do sono.

Ryu, Park e Park ${ }^{103}$ desenvolveram um ensaio clínico cujo objetivo foi testar a efetividade da música em pacientes submetidos à revascularização percutânea do miocárdio. A música foi fornecida aos pacientes do grupo experimental por meio de fones de ouvido e o grupo controle recebeu apenas tampões de ouvidos sem produção sonora. Os resultados revelaram que a qualidade e a quantidade do sono foram significativamente maiores entre os pacientes do grupo experimental. Os autores afirmam ainda que a música reduz ou controla o estresse e promove conforto e relaxamento. Lai e Good ${ }^{104}$, com base em uma teoria psicofisiológica, referem que a música induz o relaxamento e a distração com redução da resposta neuroendócrina do estresse, avaliada por meio da redução da frequência cardíaca, pressão arterial, frequência respiratória e melhora do sono ${ }^{105}$.

$\mathrm{Na}$ presente pesquisa as técnicas de relaxamento compreendem massagem, relaxamento muscular progressivo e treino de postura e relaxamento. Os resultados do estudo de Akinci et al. ${ }^{90}$ mostraram melhora significativa do sono, evidenciada pelo escore total do PSQI, de pacientes submetidos à cirurgia cardíaca após a intervenção nomeada programa de treinamento de postura e relaxamento. Os efeitos benéficos do programa também foram evidenciados com relação à diminuição do uso de medicamentos para dormir, melhora da qualidade de vida e da qualidade do sono percebida pelo paciente e menor escore de dor. Conclui-se que a intervenção utilizada contribui para deambulação precoce e consequente recuperação do paciente, é um método seguro e bem tolerado pelos pacientes e independe de equipamentos e dispositivos.

Os resultados do estudo de Ranjbaran et al. ${ }^{91}$ evidenciaram que a técnica de relaxamento muscular progressivo melhora significativamente a qualidade do sono de pacientes submetidos à cirurgia cardíaca. No entanto, mesmo considerando a melhora significativa, verifica-se a necessidade de melhor rigor metodológico para a construção do estudo. Na avaliação de escore de Jadad, o estudo não descreve o motivo que levou à desistência ou retirada dos participantes, assim como não se inclui a dupla ocultação dos seus examinandos ou examinadores. Fica evidente a 
necessidade de novos estudos com delineamentos corretos e robustos que possa garantir melhor confiabilidade de suas análises. Corroborando esses achados, a técnica de relaxamento muscular progressivo, descrita como "estica e relaxa", oferece resposta significativa na melhoria do padrão do sono ${ }^{106}$.

Nessa perspectiva, resultados de diferentes pesquisas mostram o impacto da privação do sono na esfera fisiológica e comportamental dos indivíduos. A qualidade do sono está diretamente relacionada à recuperação física e emocional do paciente crítico $^{18}$. O estudo de Barnason et al. ${ }^{107}$ mostrou que pacientes fadigados após a cirurgia cardíaca apresentaram significativa piora de escores na avaliação do humor, bem-estar emocional e função social em comparação aos não fadigados. Os autores desse estudo concluem que, para promover a recuperação de pacientes após cirurgia cardíaca, é importante considerar ações que limitarão a fadiga por meio de uma adequada intervenção que promova um período de sono noturno.

Conway, Nebauer e Schulz ${ }^{83}$ também relatam alívio da ansiedade e da dor por meio da terapia de relaxamento muscular progressivo. Os autores desse estudo ainda referem a necessidade de inclusão das técnicas de relaxamento na prática do cuidado.

Sendo assim, percebe-se que os enfermeiros devem considerar o sono parte da prática de enfermagem, a fim de garantir a adequada recuperação do paciente, a redução de complicações e a diminuição do tempo de internação hospitalar e dos custos. Greve e Pedersen ${ }^{84}$ acreditam que enfermeiros com maior conhecimento sobre o sono e seus princípios de higiene apresentam efeitos sobre a qualidade do sono percebida pelo paciente e podem diminuir as consequências de um sono ruim.

A avaliação do sono realizada pelo enfermeiro é primordial para garantir a recuperação do paciente e a detecção precoce dos pacientes que apresentam alterações. O planejamento das intervenções de enfermagem para este sintoma contribui para melhorar a qualidade do sono dos pacientes internados e com a plena recuperação. $O$ enfermeiro deve programar as atividades de cuidado rotineiras para um horário que minimize as interrupções de sono e proporcione um período de sono noturno restaurador ${ }^{20}$.

Um ensaio clínico ${ }^{89}$ incluído na atual revisão testou a efetividade da massagem entre pacientes em pós-operatório de cirurgia cardíaca e não alcançou 
melhoria significativa sobre a qualidade do sono. Outros estudos com populações distintas testaram a massagem como método para promoção do sono. Richards ${ }^{108}$ realizou um ensaio clínico com o objetivo de testar a efetividade da massagem nas costas sobre a qualidade do sono de idosas cardiopatas internadas em UTI. Os resultados mostraram melhora significativa no índice de eficiência do sono entre as participantes que receberam a intervenção.

O estudo de MacCune ${ }^{82}$ testou a efetividade da massagem sobre a qualidade do sono entre pacientes submetidos à cirurgia cardíaca e os resultados mostraram melhora significativa.

O único estudo brasileiro ${ }^{89}$ que avaliou o uso da massagem como método único na promoção do sono de pacientes submetidos à cirurgia cardíaca apresentou baixa qualidade metodológica e sem significância em seus resultados. Isso reforça a necessidade de se elaborar estudos com melhor delineamento, a fim de se garantir evidências de qualidade que possam ser inseridas na prática clínica do cuidado de enfermagem.

Guo, East e Arthur ${ }^{96}$ testaram a efetividade de uma intervenção educacional em pacientes no período pré-operatório de cirurgia cardíaca com o intuito de reduzir os níveis de ansiedade e melhora da recuperação após a cirurgia. Os resultados do estudo evidenciaram melhora significativa sobre os escores de ansiedade e depressão. Além disso, os pacientes relataram interferência significativamente menor da dor sobre a capacidade de dormir em comparação aos que não receberam a intervenção educacional. O estudo refere ser uma técnica simples, de fácil aplicação e aceitação. Sendo assim, conclui-se que a educação ao paciente deva fazer parte do processo de enfermagem e, assim, incentivada na prática clínica.

Outros estudos encontrados na literatura indicam que estratégias educacionais alcançam resultados satisfatórios sobre a recuperação dos pacientes cirúrgicos. Zhang et al. ${ }^{109}$ testaram uma intervenção baseada em educação préoperatória sobre aspectos gerais da cirurgia, internação na UTI e recuperação. Os autores concluíram que a intervenção é associada à redução de complicações e escore de ansiedade em pacientes no período pós-operatório de cirurgia cardíaca. Nesse estudo, os enfermeiros foram os responsáveis por programar a intervenção. 
Zhang et al. ${ }^{109}$ referem a necessidade de o enfermeiro adquirir conhecimentos sobre os cuidados na promoção do sono para atuar ativamente na redução dos fatores que impactam na piora da qualidade do sono e suas consequências na recuperação do paciente. 
7 CONCLUSÕES 
No presente estudo, buscou-se evidências disponíveis sobre as intervenções não farmacológicas para o tratamento da alteração do padrão do sono em pacientes após procedimentos cirúrgicos cardíacos.

Em relação ao ano de publicação, os estudos se distribuíram entre 1992 e 2016, com prevalência dos últimos cinco anos com seis estudos publicados sobre o assunto. Esses resultados mostram que a alteração do padrão do sono é um tema mais recentemente estudado.

Dentre os países de origem das publicações observa-se predomínio dos Estados Unidos da América com quatro estudos. Os resultados da presente revisão mostram que os pesquisadores brasileiros pouco pesquisam na área e contribuíram com apenas um artigo publicado.

Todos os estudos selecionados para a atual revisão eram na língua inglesa, o que indica escassez de estudos sobre cuidados com o sono em âmbito nacional. $\mathrm{Na}$ realidade brasileira, os enfermeiros podem considerar o idioma das publicações uma limitação ao acesso às melhores evidências.

As revistas em que foram publicados os artigos selecionados foram diversificadas, cada periódico com apenas um estudo publicado. Os resultados mostram que há publicações tanto em revistas científicas de enfermagem, como nas revistas da área médica.

Uma das limitações apresentadas pelos estudos analisados na atual revisão foi com relação à qualidade metodológica. Foram considerados de baixa qualidade $50 \%$ dos ensaios clínicos e os outros $50 \%$ de moderada qualidade. Observa-se que não foram encontrados estudos considerados de alta qualidade pelo escore de Jadad. O quesito da avaliação "estudo descrito como duplo-cego" foi ausente em todos os ensaios clínicos. Entre os estudos classificados como baixa qualidade metodológica, todos foram descritos como randomizados, porém nenhum descreveu esse método de maneira apropriada conforme escore de Jadad. Os resultados da atual revisão permitem fazer reflexões sobre a necessidade de produção de conhecimento científico com melhor qualidade na área e com rigor metodológico que 
permita obter resultados confiáveis e que possam ser aplicados na prática do cuidado.

$\mathrm{Na}$ síntese das evidências disponíveis dos estudos incluídos na revisão identificou-se que estes enfocaram três categorias principais: quatro estudos testaram dispositivos para minimizar a interrupção do sono e/ou sua indução; três ensaios clínicos investigaram a eficácia de técnicas de relaxamento e três estudos primários avaliaram a efetividade de intervenções educacionais.

De acordo com a análise dos artigos compreende-se que houve melhoria significativa nos escores de avaliação do sono em estudos que testaram intervenções como tampões de ouvidos, máscara de olhos, relaxamento muscular, treinamento de postura e relaxamento, produção sonora e estratégia educacional.

A maioria dos artigos mostra melhora nas seguintes variáveis de qualidade do sono: eficiência, profundidade, duração total, latência, percepção de melhoria da qualidade do sono pelo paciente, sonolência diurna, número de despertares durante o sono e uso de medicamentos para dormir.

Os resultados sugerem que as intervenções não farmacológicas para promoção do sono contempladas nos estudos selecionados podem ser planejadas, executadas e avaliadas por enfermeiros. Nesse contexto, o enfermeiro tem papel essencial na tomada de decisão, garantindo a restauração e recuperação física e emocional do paciente. Por meio de uma correta avaliação do paciente, o enfermeiro pode identificar o problema "dificuldade para dormir". Após o primeiro passo, de avaliação, o enfermeiro é capaz de alcançar excelentes resultados sobre a recuperação do paciente por meio de ações como planejar intervenções não farmacológicas, implementar, avaliar criticamente, evoluir os resultados, educar a equipe de saúde e programar melhorias.

Visto que são frequentes as queixas dos pacientes sobre luminosidade e ruído excessivos durante a internação hospitalar, reforça-se a necessidade de os enfermeiros valorizarem os relatos dos pacientes. Entre as equipes de saúde há muita ênfase sobre a redução do barulho e da luz, especialmente no período noturno. No entanto, existem pacientes que necessitam de cuidados intensivos durante tempo integral. A diminuição da luminosidade e do volume dos alarmes de equipamentos pode prejudicar a assistência. Além disso, tentativas para minimizar 
as conversas e o tom de voz entre os membros da equipe envolve um trabalho educativo e comportamental.

Sendo assim, intervenções não farmacológicas como máscara para olhos, tampões de ouvidos e aparelhos com produção musical tornam-se as melhores alternativas para preservar e promover o sono dos pacientes. Além disso, essas intervenções são viáveis, bem toleradas, simples e economicamente acessíveis.

A revisão sistemática mostrou lacunas no conhecimento acerca da problemática investigada. Assim, espera-se encorajar a condução de futuras pesquisas que enfoquem a utilização de medidas não farmacológicas para promoção do sono de pacientes submetidos à cirurgia cardíaca para a indicação das mais eficazes intervenções.

No contexto da prática clínica real, acredita-se que os enfermeiros realizam muitas das intervenções não farmacológicas mencionadas nessa revisão. No entanto, não há estudos publicados, o que dificulta a síntese das melhores evidências que possam ser recomendadas na prática do cuidado. 
8 REFERÊNCIAS 
1- Casida JM, Davis JE, Shpakoff L, Yarandi H. An exploratory study of the patients' sleep patterns and inflammatory response following cardiopulmonary bypass CPB. J Clin Nurs. 23(15-16):2332-42.

2- Redeker NS, McEnany GP, editors. Sleep disorders and sleep promotion in nursing practice. New York: Springer; 2011.

3- Anch M, Browman CP, Mitler MM, Walsh JK. Sleep: a scientific perspective. Englewood Cliffs, NJ: Prentice-Hall, 1988.

4- Oswald I. Sleep the great restorer. New Sci. 1970;46:170-2.

5- Iber C. The AASM manual for the scoring of sleep and associated events: rules, terminology and technical specifications. Westchester, IL: American Academy of Sleep Medicine; 2007.

6- Harvey AG, Stinson K, Whitaker KL, Moskovitz D, Virk H. The subjective meaning of sleep quality: a comparison of individuals with and without insomnia. Sleep. 2008;31(3):383-93.

7- Bourne RS, Minelli C, Mills GH, Kandler R. Clinical review: Sleep measurement in critical care patients: research and clinical implications. Crit Care. 2007;11(4):226.

8- Morgenthaler TI, Lee-Chiong T, Alessi C, Friedman L, Aurora RN, Boehlecke $B$, et al. Practice parameters for the clinical evaluation and treatment of circadian rhythm sleep disorders. An American Academy of Sleep Medicine report. Sleep. 2007; 30(11):1445-59.

9- Littner M, Kushida CA, Anderson WM, Bailey D, Berry RB, Davila DG, et al. Practice parameters for the role of actigraphy in the study of sleep and circadian rhythms: an update for 2002. Sleep. 2003;26(3):337-41.

10-Martin JL, Hakim AD. Wrist actigraphy. Chest. 2011;139(6):1514-27.

11-Ancoli-Israel S, Clopton P, Klauber MR, Fell R, Mason W. Use of wrist activity for monitoring sleep/wake in demented nursing-home patients. Sleep. 1997;20(1):24-7.

12-Liao WC, Huang CY, Huang TY, Hwang SL. A systematic review of sleep patterns and factors that disturb sleep after heart surgery. J Nurs Res. 2011;19(4):275-88. 
13-Berger AM, Parker KP, Young-McCaughan S, Mallory GA, Barsevick AM, et al. Sleep wake disturbances in people with cancer and their caregivers: state of the science. Oncol Nurs Forum. 2005;32(6):E98-126.

14-Bergamasco EC, Cruz DALM. Adaptação da visual analog sleep scales para a língua portuguesa. Rev Latino-am Enfermagem. 2007; 15(5).

15-Ohayon MM, Carskadon MA, Guilleminault C, Vitiello MV. Meta-analysis of quantitative sleep parameters from childhood to old age in healthy individuals: developing normative sleep values across the human lifespan. Sleep. $2004 ; 27(7): 1255-73$.

16-Hoey LM, Fulbrook P, Douglas JA. Sleep assessment of hospitalised patients: a literature review. Int J Nurs Stud. 2014;51(9):1281-8.

17-Redeker NS, Hedges C. Sleep during hospitalization and recovery after cardiac surgery. J Cardiovasc Nurs. 2002;17(1):56-68.

18-Kamdar BB, Needham DM, Collop NA. Sleep deprivation in critical illness: its role in physical and psychological recovery. J Intensive Care Med. 2012;27(2):97-111.

19-Casida JM, Nowak L. Integrative therapies to promote sleep in the intensive care unit. In: Chlan L, Hertz M, editors. Integrated therapies in lung health \& sleep. New York: Springer; 2011. p.177-87.

20-da Costa SV, Ceolim MF. Fatores que interferem na qualidade do sono de pacientes internados. Rev Esc Enferm USP. 2013;47(1):46-52.

21-Simpson T, Lee ER, Cameron C. Patients' perceptions of environmental factors that disturb sleep after cardiac surgery. Am J Crit Care. 1996;5(3):17381.

22-Simpson T, Lee ER, Cameron C. Relationships among sleep dimensions and factors that impair sleep after cardiac surgery. Res Nurs Health. 1996;19(3):213-23.

23-Spence J, Murray T, Tang AS, Butler RS, Albert NM. Nighttime noise issues that interrupt sleep after cardiac surgery. J Nurs Care Qual. 2011;26(1):88-95.

24-Zhong X, Hilton HJ, Gates GJ, Jelic S, Stern Y, Bartels MN, et al. Increased sympathetic and decreased parasympathetic cardiovascular modulation in normal humans with acute sleep deprivation. J Appl Physiol. 2005;98(6):202432.

25-Spiegel K, Leproult R, Van Cauter E. Impact of sleep debt on metabolic and endocrine function. Lancet. 1999;354(9188):1435-9. 
26-Chen HI, Tang YR. Sleep loss impairs inspiratory muscle endurance. Am Rev Respir Dis. 1989;140(4):907-9.

27-Sauvet F, Leftheriotis G, Gomez-Merino D, Langrume C, Drogou C, Van Beers $P$, et al. Effect of acute sleep deprivation on vascular function in healthy subjects. J Appl Physiol. 1985. 2010;108(1):68-75.

28-Frey DJ, Fleshner M, Wright KP Jr. The effects of 40 hours of total sleep deprivation on inflammatory markers in healthy young adults. Brain Behav Immun. 2007;21(8):1050-7.

29-Hossin MZ. From habitual sleep hours to morbidity and mortality: existing evidence, potential mechanisms, and future agenda. Sleep Health. 2016; 2(2):146-53.

30-Cappuccio FP, Cooper D, D'Elia L, Strazzullo P, Miller MA. Sleep duration predicts cardiovascular outcomes: a systematic review and meta-analysis of prospective studies. Eur Heart J. 2011;32(12):1484-92.

31-Hublin C, Partinen M, Koskenvuo M, Kaprio J. Sleep and mortality: a population-based 22-year follow-up study. Sleep. 2007;30(10):1245-53.

32-Hammond EC. Some preliminary findings on physical complaints from a prospective study of 1,064,004 men and women. Am J Public Health Nations Health 1964;54:11-23.

33-Ikehara S, Iso H, Date C, Kikuchi S, Watanabe Y, Wada Y, et al. Association of sleep duration with mortality from cardiovascular disease and other causes for Japanese men and women: the JACC study. Sleep. 2009;32(3):295-301.

34-Kripke DF, Garfinkel L, Wingard DL, Klauber MR, Marler MR. Mortality associated with sleep duration and insomnia. Arch Gen Psychiatry. 2002;59(2):131-6.

35-Meier-Ewert HK, Ridker PM, Rifai N, Regan MM, Price NJ, Dinges DF, et al. Effect of sleep loss on C-reactive protein, an inflammatory marker of cardiovascular risk. J Am Coll Cardiol. 2004;43(4):678-83.

36-Knutson KL, Van Cauter E. Associations between sleep loss and increased risk of obesity and diabetes. Ann N Y Acad Sci. 2008;1129:287-304.

37-World Health Organization. Cardiovascular diseases CVDs: Fact sheet. [Reviewed September 2016; cited 2015 March 22]. Available from: http://www.who.int/mediacentre/factsheets/fs317/en/.

38-Oliveira Junior MT, Canesin MF, Marcolino MS, Ribeiro ALP, Carvalho ACC, Reddy S, et al. Diretriz de telecardiologia no cuidado de pacientes com 
síndrome coronariana aguda e outras doenças cardíacas. Arq Bras Cardiol. 2015; 104(5 Suppl 1):1-26.

39-Moran AE, Forouzanfar MH, Roth GA, Mensah GA, Ezzati M, Murray CJ, et al. Temporal trends in ischemic heart disease mortality in 21 world regions, 1980 to 2010: the Global Burden of Disease 2010 study. Circulation. 2014;129(14):1483-92.

40-Cesar LA, Ferreira JF, Armaganijan D, Gowdak LH, Mansur AP, Bodanese LC, et al. Diretriz de doença coronária estável. Arq Bras Cardiol. 2014; 103 (2 supl. 2):1-59.

41-Tarasoutchi F, Montera MW, Grinberg M, Barbosa MR, Piñeiro DJ, Sánchez CRM, et al. Diretriz brasileira de valvopatias - SBC 2011. Arq Bras Cardiol. 2011; 97(5 supl.1):1-67.

42-Mansur AP, Favarato D. Mortalidade por doenças cardiovasculares no Brasil e na região metropolitan de São Paulo: atualização 2011. Arq Bras Cardiol. 2012;99(2):755-61.

43-Brasil. Ministério da Saúde. DATASUS. Sistema de informações de mortalidade. Óbitos por residência por ano do óbito segundo capítulo CID-10. [Cited 2015 May 15]. Available from: http://www.datasus.gov.br.

44-Mozaffarian D, Benjamin EJ, Go AS, Arnett DK, Blaha MJ, Cushman M, et al. Heart disease and stroke statistics--2015 update: a report from the American Heart Association. Circulation. 2015;131(4):e29-322.

45-Smith SC Jr, Benjamin EJ, Bonow RO, Braun LT, Creager MA, Franklin BA, et al. AHA/ACCF Secondary Prevention and Risk Reduction Therapy for Patients with Coronary and other Atherosclerotic Vascular Disease: 2011 update: a guideline from the American Heart Association and American College of Cardiology Foundation. Circulation. 2011;124(22):2458-73.

46-Hillis LD, Smith PK, Anderson JL, Bittl JA, Bridges CR, Byrne JG, et al. 2011 ACCF/AHA guideline for coronary artery bypass graft surgery: executive summary: a report of the American College of Cardiology Foundation/American Heart Association Task Force on Practice Guidelines. Circulation. 2011;124(23):2610-42.

47-Szczepanska-Gieracha J, Morka J, Kowalska J, Kustrzycki W, Rymaszewska $\mathrm{J}$. The role of depressive and anxiety symptoms in the evaluation of cardiac rehabilitation efficacy after coronary artery bypass grafting surgery. Eur $\mathrm{J}$ Cardiothorac Surg. 2012;42(5):e108-14. 
48-Epstein AJ, Polsky D, Yang F, Yang L, Groeneveld PW. Coronary revascularization trends in the United States: 2001-2008. JAMA. 2011;305(17):1769-76.

49-Lima RC, Kubrusly LF, Nery AC, Pinheiro BB, Brick AV, de Souza DS, et al. Diretrizes da Cirurgia de revascularização miocárdica. Arq Bras Cardiol. 2004;8(2Suppl 5):1-20.

50-Sawatzky JAV, Christie S, Singal RK. Exploring outcomes of a nurse practitioner-managed cardiac surgery follow-up intervention: a randomized trial. J Adv Nurs. 2013;69(9):2076-87.

51-Head SJ, Kieser TM, Falk V, Huysmans HA, Kappetein AP. Coronary artery bypass grafting. Part 1 . The evolution over the first 50 years. Eur Heart $\mathrm{J}$. 2013;34(37):2862-72.

52-Palmerini T, Biondi-Zoccai G, Reggiani LB, Sangiorgi D, Alessi L, De Servi S, et al. Risk of stroke with coronary artery bypass graft surgery compared with percutaneous coronary intervention. J Am Coll Cardiol. 2012;60(9):798-805.

53-Lamy A, Devereaux PJ, Prabhakaran D. Off-pump or on-pump coronary-artery bypass grafting at 30 Days. N Engl J Med. 2012; 366(16):1489-1497.

54-Redeker NS, Ruggiero J, Hedges C. Patterns and predictors of sleep pattern disturbance after cardiac surgery. Res Nurs Health. 2004;27(4):217-24.

55-Bojar RM. Manual of perioperative care in adult cardiac surgery. $5^{\text {th }}$ ed. Hoboken, NJ: Wiley-Blackwell; 2011.

56-Edéll-Gustafsson UM, Hetta JE, Arén CB. Sleep and quality of life assessment in patients undergoing coronary artery bypass grafting. $\mathrm{J} A d v$ Nurs.1999;29(5):1213-20.

57-Abbott AA, Barnason S, Zimmerman L. Symptom burden clusters and their impact on psychosocial functioning following coronary artery bypass surgery. $\mathrm{J}$ Cardiovasc Nurs. 2010;25(4):301-10.

58-McKinley S, Fien M, Elliott R, Elliott D. Sleep and psychological health during early recovery from critical illness: an observational study. J Psychosom Res. 2013;75(6):539-45.

59-Pröpper J, van Valen R, van Domburg RT, Brunott M, Bogers AJJC. Quality of sleep at the ward after cardiothoracic surgery. Open J Nurs. 2015; 5:529-37.

60-Edéll-Gustafsson U, Arén C, Hamrin E, Hetta J. Nurses' notes on sleep patterns in patients undergoing coronary artery bypass surgery: a retrospective evaluation of patient records. J Adv Nurs. 1994;20(2):331-6. 
61-Redeker NS. Sleep in acute care settings: an integrative review. J Nurs Scholarsh. 2000;32(1):31-8.

62-Tamburri LM, DiBrienza R, Zozula R, Redeker NS. Nocturnal care interactions with patients in critical care units. Am J Crit Care. 2004;13(2):102-12.

63-Ligações entre NANDA, NOC e NIC: diagnósticos, resultados e intervenções de enfermagem / Marion Johnson ... [et al.]; tradução Regina Machado Garcez. - 2.ed. - Porto Alegre: Artmed, 2009. 704 p.

64-Bourne RS, Mills GH. Sleep disruption in critically ill patients: pharmacological considerations. Anaesthesia. 2004;59(4):374-84.

65-Hu RF, Jiang XY, Zeng YM, Chen XY, Zhang YH. Effects of earplugs and eye masks on nocturnal sleep, melatonin and cortisol in a simulated intensive care unit environment. Crit Care. 2010;14(2):R66.

66-Hu RF, Jiang XY, Hegadoren KM, Zhang YH. Effects of earplugs and eye masks combined with relaxing music on sleep, melatonin and cortisol levels in ICU patients: a randomized controlled trial. Crit Care. 2015;19:115.

67-Le Guen M, Nicolas-Robin A, Lebard C, Arnulf I, Langeron O. Earplugs and eye masks vs routine care prevent sleep impairment in post-anaesthesia care unit: a randomized study. Br J Anaesth. 2014;112(1):89-95.

68-Tamrat R, Huynh-Le MP, Goyal M. Non-pharmacologic interventions to improve the sleep of hospitalized patients: a systematic review. J Gen Intern Med. 2014;29(5):788-95.

69-Chee JK, Yeat CL, Abdulkareem ZA, Barton-Burke M. Non-pharmacological interventions for the treatment of sleep-wake disturbances in patients with cancer. Cochrane Database Syst Rev. 2015; 3:CD011576.

70-Zimmerman L, Barnason S, Young L, Tu C, Schulz P, Abbott AA. Symptom profiles of coronary artery bypass surgery patients at risk for poor functioning outcomes. J Cardiovasc Nurs. 2010;25(4):292-300.

71-Sackett DL, Straus SE, Richardson WS, Rosenberg W, Haynes RB. Medicina baseada em evidências. $2^{\mathrm{a}}$ ed. Porto Alegre, RS: Artmed; 2003.

72-Akobeng AK. Principles of evidence based medicine. Arch Dis Child. 2005;90(8):837-40.

73-The Cochrane Collaboration. Glossary of terms in The Cochrane Collaboration [Internet]. Version 4.2.5. London:; 2005 [Cited 2016 Aug 30]. Available from: http://community.cochrane.org/sites/default/files/uploads/glossary.pdf 
74-Brasil. Ministério da Saúde. Secretaria de Ciência, Tecnologia e Insumos Estratégicos. Departamento de Ciência e Tecnologia. Diretrizes metodológicas: elaboração de revisão sistemática e metanálise de ensaios clínicos randomizados. Brasília, DF; 2012. 92p.

75-Bernardo WM, Nobre MRC, Biscegli FJ. A prática clínica baseada em evidências. Parte II. Buscando as evidências em fontes de informação. Rev Bras Reumatol. 2004; 44(6):403-9.

76-Dicenso A, Cullum N. Implementing evidence based nursing: some misconceptions. Evid Based Nurs 1998; 12:38-40

77-Nobre M, Bernardo W. Prática clínica baseada em evidência. Rio de Janeiro: Elsevier; 2007.

78-Fletchter RH, Fletcher SW. Epidemiologia clínica: elementos essenciais. $4^{a}$ ed. Porto Alegre, RS: Artmed; 2006.

79-Melnyk BM, Fineout-Overholt $\mathrm{H}$. Evidence-based practice in nursing and healthcare: a guide to best practice. Philadelphia: Lippincott Williams \& Wilkins; 2011.

80-Nobre MRC, Bernardo WM, Jatene FB. A prática clínica baseada em evidências. Parte I. Questões clínicas bem construídas. Rev Assoc Med Bras. 2003; 49(4):445-9.

81-Ursi ES. Prevenção de lesões de pele no perioperatório: revisão integrativa da literatura [internet]. Ribeirão Preto, SP: Escola de Enfermagem de Ribeirão Preto; 2005. [citado 2016 Mai 20]. Disponível em: http://www.teses.usp.br/teses/disponiveis/22/22132/tde-18072005-095456/ptbr.php

82-MacCune S. Effect of back massage on sleep among post-operative CABG and valve replacement patients. Nurs J India. 2010;101(4):86-8.

83-Conway A, Nebauer M, Schulz P. Improving sleep quality for patients after cardiac surgery. Br J Card Nurs. 2010; 5(3):142-7.

84-Greve H, Pedersen PU. Improving sleep after open heart surgery: Effectiveness of nursing interventions. J Nurs Educ Pract. 2016; 6(3):15-25.

85-Moher D, Liberati A, Tetzlaff J, Altman DG; PRISMA Group. Preferred reporting items for systematic reviews and meta-analyses: the PRISMA statement. Ann Intern Med. 2009;151(4):264-9, W64. 
86-Silva Filho CR da, Saconato Hm Conterno LO, Marques I, Atallah AN. Avaliação da qualidade de estudos clínicos e seu impacto nas metanálises. Rev Saúde Pública. 2005; 396:865-73.

87-Zanetta DMT. Delineamento de estudos em medicina. In: Massad E, Menezes RX, Silveira PS, Ortega NRS, editores. Métodos quantitativos em Medicina. Barueri, SP: Manole; 2004. p.389-421.

88-Jadad AR, Moore RA, Carroll D, Jenkinson C, Reynolds DJ, Gavaghan DJ, et al. Assessing the quality of reports of randomized clinical trials: is blinding necessary? Control Clin Trials. 1996;17(1):1-12.

89-Nerbass FB, Feltrim MI, Souza SA, Ykeda DS, Lorenzi-Filho G. Effects of massage therapy on sleep quality after coronary artery bypass graft surgery. Clinics (São Paulo). 2010;65(11):1105-10.

90-Akinci B, Yeldan I, Bayramoğlu Z, Akpınar TB.The effects of posture and relaxation training on sleep, dyspnea, pain and, quality of life in the short-term after cardiac surgery: a pilot study. Turk Gogus Kalp Dama. 2016;24(2):25865.

91-Ranjbaran S, Dehdari T, Sadeghniiat-Haghighi K, Majdabadi MM. Poor sleep quality in patients after coronary artery bypass graft surgery: an intervention study using the PRECEDE-PROCEED Model. J Teh Univ Heart Ctr. 2015;10(1):1-8.

92-Casida JM, Yaremchuk KL, Shpakoff L, Marrocco A, Babicz G, Yarandi H. The effects of guided imagery on sleep and inflammatory response in cardiac surgery: a pilot randomized controlled trial. J Cardiovasc Surg (Torino). 2013;54(2):269-79.

93-Zimmerman L, Nieveen J, Barnason S, Schmaderer M. The effects of music interventions on postoperative pain and sleep in coronary artery bypass graft (CABG) patients. Sch Inq Nurs Pract. 1996;10(2):153-70; discussion 171-4.

94-Williamson JW. The effects of ocean sounds on sleep after coronary artery bypass graft surgery. Am J Crit Care. 1992;1(1):91-7.

95-Zimmerman L, Barnason S, Schulz P, Nieveen J, Miller C, Hertzog M, et al. The effects of a symptom management intervention on symptom evaluation, physical functioning, and physical activity for women after coronary artery bypass surgery. J Cardiovasc Nurs. 2007;22(6):493-500.

96-Guo P, East L, Arthur A. A preoperative education intervention to reduce anxiety and improve recovery among Chinese cardiac patients: a randomized controlled trial. Int J Nurs Stud. 2012;49(2):129-37. 
97-Johansson A, Adamson A, Ejdebäck J, Edéll-Gustafsson U. Evaluation of an individualised programme to promote self-care in sleep-activity in patients with coronary artery disease: a randomised intervention study. J Clin Nurs. 2014;23(19-20):2822-34.

98-Hellström A, Fagerström C, Willman A. Promoting sleep by nursing interventions in health care settings: a systematic review. Worldviews Evid Based Nurs. 2011;8(3):128-42.

99-Richardson A, Allsop M, Coghill E, Turnock C. Earplugs and eye masks: do they improve critical care patients' sleep? Nurs Crit Care. 2007;12(6):278-86.

100- Neyse F, Daneshmandi M, Sharme MS, Ebadi A. The effect of earplugs on sleep quality in patients with acute coronary syndrome. Iran J Crit Care Nurs. 2011;4(3):127-34.

101- Stanchina ML, Abu-Hijleh M, Chaudhry BK, Carlisle CC, Millman RP. The influence of white noise on sleep in subjects exposed to ICU noise. Sleep Med. 2005;6(5):423-8.

102- $\quad$ Su CP, Lai HL, Chang ET, Yiin LM, Perng SJ, Chen PW. A randomized controlled trial of the effects of listening to non-commercial music on quality of nocturnal sleep and relaxation indices in patients in medical intensive care unit. J Adv Nurs. 2013;69(6):1377-89.

103-Ryu MJ, Park JS, Park H. Effect of sleep-inducing music on sleep in persons with percutaneous transluminal coronary angiography in the cardiac care unit. J Clin Nurs. 2012; 21(5-6):728-35.

104-Lai HL, Good M. Music improves sleep quality in older adults. J Adv Nurs. 2005;49(3):234-44.

105-Zatorre R, McGill J. Music, the food of neuroscience? Nature. 2005;434(7031):312-5.

106-Payne R. Relaxation techniques: a practical handbook for the health professional. Lansing, Ml: Churchill Livingstone; 1995.

107-Barnason S, Zimmerman L, Nieveen J, Schulz P, Miller C, Hertzog M, et al. Relationships between fatigue and early postoperative recovery outcomes over time in elderly patients undergoing coronary artery bypass graft surgery. Heart Lung. 2008;37(4):245-56.

108- Richards KC. Effect of a back massage and relaxation intervention on sleep in critically ill patients. Am J Crit Care. 1998;7(4):288-99. 
109-Zhang CY, Jiang Y, Yin QY, Chen FJ, Ma LL, Wang LX. Impact of nurseinitiated preoperative education on postoperative anxiety symptoms and complications after coronary artery bypass grafting. J Cardiovasc Nurs. 2012;27(1):84-8. 
APÊNDICE 


\section{Instrumento para coleta de dados (validado por Ursi ${ }^{81}$ )}

\begin{tabular}{|c|c|}
\hline \multicolumn{2}{|l|}{ A. Identificação } \\
\hline \multicolumn{2}{|l|}{ Título do artigo } \\
\hline \multicolumn{2}{|l|}{ Título do periódico } \\
\hline \multicolumn{2}{|l|}{ Autores } \\
\hline \multicolumn{2}{|l|}{ País } \\
\hline \multicolumn{2}{|l|}{ Idioma } \\
\hline \multicolumn{2}{|l|}{ Ano de publicação } \\
\hline \multicolumn{2}{|c|}{$\begin{array}{l}\text { B. Características } \\
\text { metodológicas do estudo }\end{array}$} \\
\hline 1. Tipo de publicação & $\begin{array}{l}1.1 \text { Pesquisa } \\
\text { ( ) Abordagem quantitativa } \\
\text { ( ) Delineamento experimental } \\
\text { ( ) Delineamento quase-experimental } \\
\text { ( ) Delineamento não-experimental } \\
\text { ( ) Abordagem qualitativa }\end{array}$ \\
\hline \multicolumn{2}{|c|}{$\begin{array}{l}\text { 2. Objetivo ou questão de } \\
\text { investigação }\end{array}$} \\
\hline 3. Amostra & 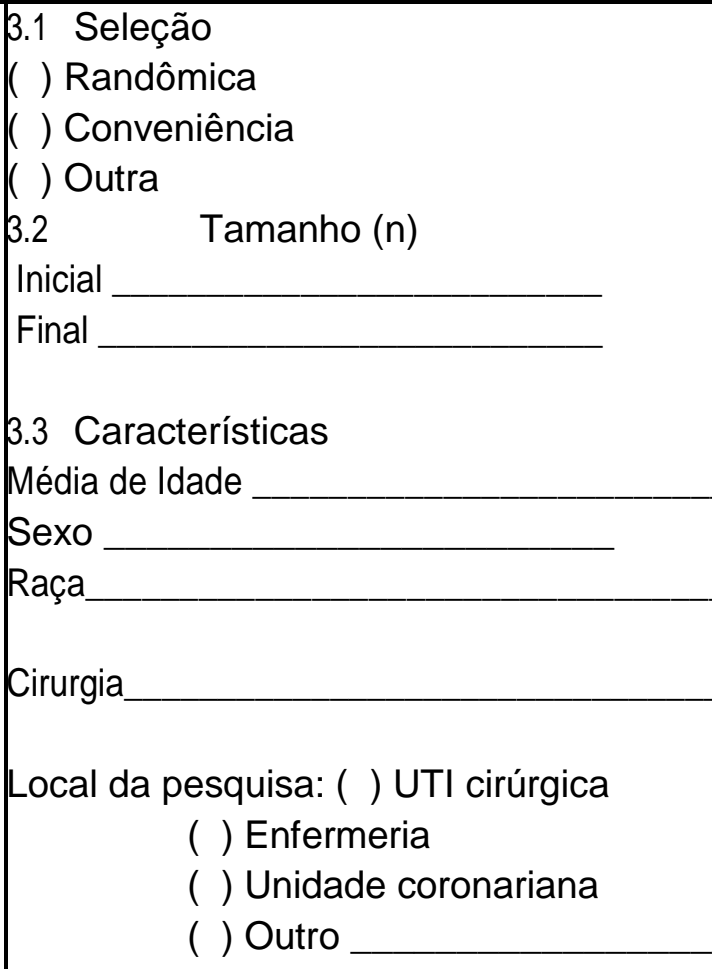 \\
\hline
\end{tabular}




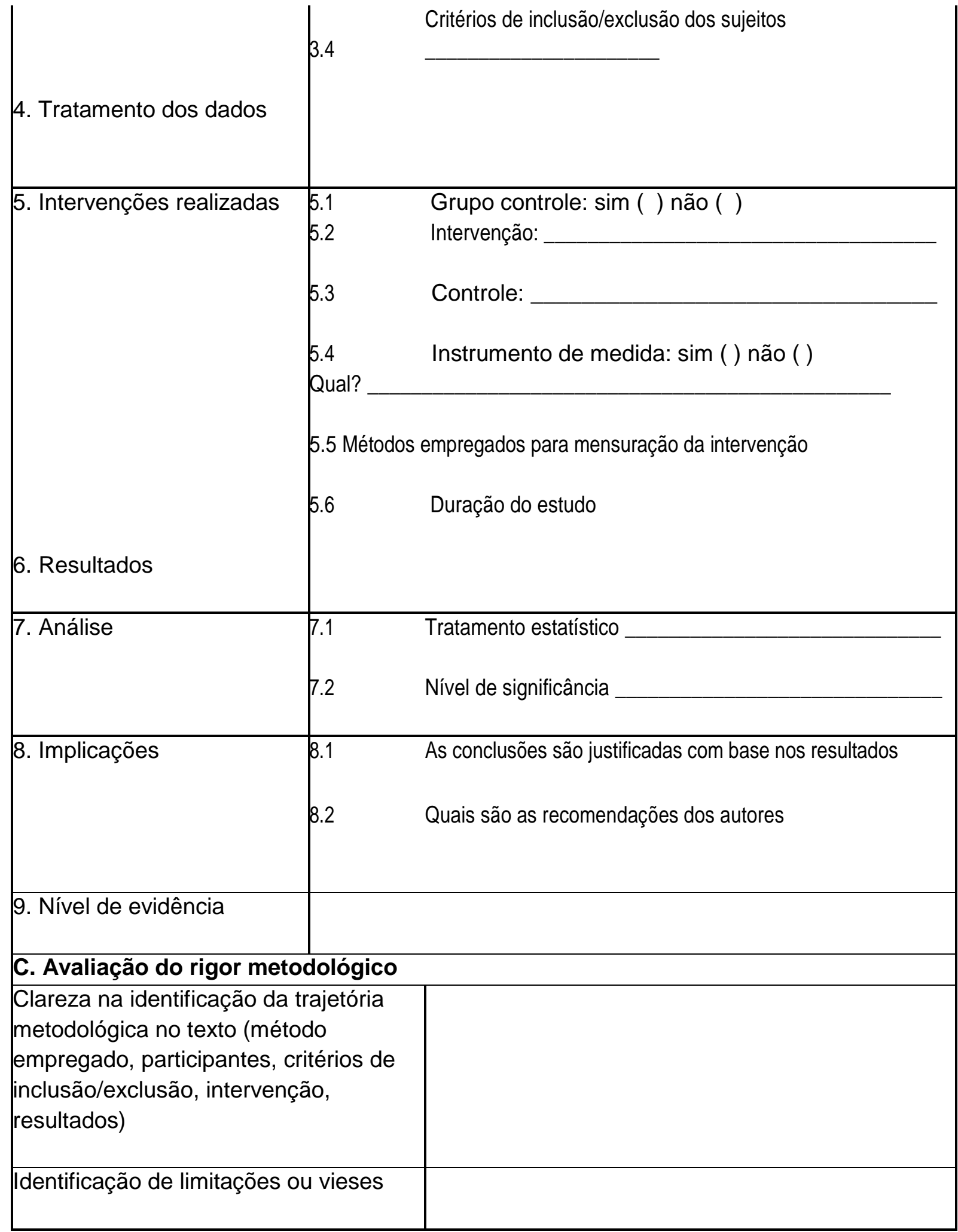

